\title{
Measurements of Freestream Fluctuations in the NASA Langley 20-Inch Mach 6 Tunnel
}

\author{
Amanda Chou* \\ NASA Langley Research Center, Hampton, VA 23681, USA \\ Andrew N. Leidy ${ }^{\dagger}$ \\ Texas A $83 M$ University, College Station, TX 77843, USA \\ Brett F. Bathel; Rudolph A. King§, and Gregory C. Herring $\mathbb{I}$ \\ NASA Langley Research Center, Hampton, VA 23681, USA
}

\begin{abstract}
An experimental campaign was conducted to measure and to characterize the freestream disturbance levels in the NASA Langley Research Center 20-Inch Mach 6 Wind Tunnel. A pitot rake was instrumented with fast pressure transducers, hot wires, and an atomic layer thermopile to quantify the fluctuation levels of pressure, mass flux, and heat flux, respectively. In conjunction with these probe-based measurements, focused laser differential interferometry was used to optically measure density fluctuations. Measurements were made at five nominal different unit Reynolds numbers ranging from $3.28-26.5 \times 10^{6} / \mathrm{m}$. The rake was positioned at two different streamwise locations and several different roll angles to measure flow uniformity within the test section. In general, noise levels were spatially consistent within the tested region. Pitot pressure fluctuation levels ranged from $0.84 \%$ at the highest Reynolds number tested to $1.89 \%$ at the lowest Reynolds number tested. Freestream mass-flux fluctuations remained relatively constant between $1.8-2.5 \%$ of the freestream. The pressure transducers were also used to determine the dominant disturbance speed and angle of propagation. The disturbances were estimated to travel at approximately $54-81 \%$ of the freestream speed at an angle of approximately $21-44^{\circ}$ from the freestream direction, but these measurements had a significant amount of uncertainty. A comparison to previous measurements of pressure made in 2012 and of mass flux made in 1994 show almost no change in the RMS fluctuation of these flow quantities.
\end{abstract}

\section{Nomenclature}

$R e_{d}$ $T_{r}$ speed of sound, $\mathrm{m} / \mathrm{s}$

frequency, $\mathrm{Hz}$

Mach number

pressure

auto-spectra density

cross-spectral density

heat flux, $\mathrm{W} / \mathrm{m}^{2}$

radial location of probe, $\mathrm{mm}$

unit Reynolds number, $\mathrm{m}^{-1}$

wire Reynolds number, $\mathrm{m}^{-1}$

recovery temperature, $\mathrm{K}$
$T_{w} \quad$ wire temperature, $\mathrm{K}$

$u \quad$ speed, $\mathrm{m} / \mathrm{s}$

$u_{r} \quad$ rate at which information travels in $x$ or $y$

$x \quad$ spanwise horizontal tunnel coordinate, $\mathrm{mm}$

$y \quad$ spanwise vertical tunnel coordinate, $\mathrm{mm}$

$z \quad$ streamwise tunnel coordinate, $\mathrm{m}$

$\gamma^{2} \quad$ coherence function

$\Delta r \quad$ probe separation distance, $\mathrm{mm}$

$\Delta t \quad$ time delay between sensors

$\Delta x \quad$ distance that a disturbance travels in $\Delta t$

$\Delta \Psi \quad$ phase difference, $\mathrm{rad} / \mathrm{s}$

\footnotetext{
*Research Aerospace Engineer, Flow Physics \& Control Branch, M/S 170, Senior Member AIAA.

${ }^{\dagger}$ Graduate Research Assistant, Student Member AIAA.

$\ddagger$ Research Physicist, Advanced Data Systems \& Measurements Branch, M/S 493, Senior Member AIAA.

$\S$ Research Aerospace Engineer, Flow Physics \& Control Branch, M/S 170, Member AIAA.

IResearch Physicist, Advanced Data Systems \& Measurements Branch, M/S 493.
} 


$\begin{array}{ll}\eta & \text { hot-wire recovery factor } \\ \mu & \text { disturbance Mach angle } \\ \rho u & \text { mass flux, } \mathrm{kg} / \mathrm{m}^{2} \cdot \mathrm{s} \\ \tau & \text { hot wire overheat ratio } \\ \phi & \text { angular orientation of rake, degrees } \\ \text { Subscript } \\ \infty & \text { freestream condition } \\ 02 & \text { pitot quantity } \\ c & \text { disturbance condition } \\ w & \text { wall condition }\end{array}$

\begin{tabular}{|c|c|}
\hline \multicolumn{2}{|c|}{ Superscript } \\
\hline , & fluctuating quantity \\
\hline Abbre? & tions and Acronyms \\
\hline ALTP & atomic layer thermopile \\
\hline a.u. & arbitrary units \\
\hline $\mathrm{CCA}$ & constant current anemometer \\
\hline CTA & constant temperature anemometer \\
\hline CVA & constant voltage anemometer \\
\hline FLDI & focused laser differential interferometr \\
\hline RMS & root-mean-square quantity \\
\hline
\end{tabular}

\section{Introduction}

Predicting the boundary-layer transition location is a critical component of aerodynamic design and can influence the control of hypersonic vehicles. In general, laminar boundary layers transition as a result of unstable disturbances that grow large, become nonlinear, and eventually break down. These disturbances can originate from a variety of sources including surface roughness/waviness and freestream disturbances. The dependence of transition on freestream disturbances underscores the importance of freestream characterization in wind-tunnel testing, particularly when these data are used to derive models of the boundary-layer transition process. Previous work has shown that these freestream disturbances have a large effect on the transition of supersonic and hypersonic models in ground test facilities. ${ }^{1-5}$

For researchers and other customers of the facility, knowledge of the magnitude and distribution of freestream flow quantities is important for knowing where to place a model. In studying transition, these quantities are particularly important to know because the mechanisms that cause transition to occur on a test article may be affected by the freestream disturbance environment. ${ }^{1,5-7}$ Simulations have started to advance so that they can incorporate knowledge of the in-flow parameters to determine the initial amplitude of instabilities in the boundary layer. ${ }^{8}$ Amplitude-based prediction models will also require some knowledge of the spectral content of these freestream disturbances. ${ }^{9}$ Thus, it has been necessary to try to quantify these freestream components to better understand the necessary inputs into our current transition models.

Previous measurements have been made to characterize the freestream fluctuations in the NASA Langley Research Center 20-Inch Mach-6 Tunnel. ${ }^{2,4,10-12}$ These measurements of freestream fluctuations are useful as a reference, but as changes to the facility flow path occur, these measurements should be repeated to ensure that the flow quality has not changed. Frequent calibration and characterization of the flow quality in hypersonic facilities may not be feasible due to cost and time constraints. Nevertheless, without occasional checks or in-depth measurements, the flow quality of these facilities can be uncertain. This paper will describe measurements made to characterize fluctuating quantities of pressure, heat transfer, mass flux, and density. Several different measurement techniques were used to measure various fluctuating quantities in the flow, including sensor-based and non-intrusive methods. From these measurements, both the RMS and frequency content of these fluctuations were obtained. An estimate of the disturbance angles and propagation speed of the acoustic disturbances were also made using these data.

\section{Experimental Methods}

\section{A. The 20-Inch Mach 6 Tunnel}

The data in this report were acquired in the NASA Langley Aerothermodynamics Laboratory (LAL) 20Inch Mach 6 Tunnel. The facility is a blow-down tunnel with quoted run times of up to 20 minutes. The maximum temperature achievable is $555.6 \mathrm{~K}$ and the nominal operating pressure range is from $206.8 \mathrm{kPa}$ to $3275 \mathrm{kPa} .{ }^{13}$ Previous measurements of the acoustic noise in the facility by Rufer and Berridge show that the normalized noise level decreased with increasing Reynolds number and was approximately $1 \%$ of the pitot pressure at a freestream unit Reynolds number of $23 \times 10^{6} / \mathrm{m} .{ }^{12}$ For the experiment presented in this paper, the total temperature was held relatively constantly at $493.4 \pm 2.3 \mathrm{~K}$ and the total pressure was varied to achieve nominal freestream unit Reynolds numbers ranging from $3.28 \times 10^{6} / \mathrm{m}$ to $26.5 \times 10^{6} / \mathrm{m}$.

Measurements were made at $z=2.149 \mathrm{~m}$ and $2.250 \mathrm{~m}$ from the throat in this experiment. These 
locations correspond to approximately $76 \mathrm{~mm}$ from the leading edge of the floor-plate of the injection system and approximately $76 \mathrm{~mm}$ ahead of the center of rotation for the model attitude control system (shown in Fig. 1b), respectively. These measurements are approximately $356 \mathrm{~mm}$ and $241 \mathrm{~mm}$ farther upstream than the farthest forward station presented in Fig. 11 of Ref. 12. The dimensions of the nozzle at these measurement stations are $521 \mathrm{~mm}$ (20.5 in.) between the contoured walls and $508 \mathrm{~mm}(20 \mathrm{in}$.) between the flat sidewalls. By taking measurements at a farther forward location, these measurements were intended to be useful in defining the in-flow conditions of computational boundaries. The coordinate system used for these measurements is as shown in Fig. 1. The streamwise station of the rake is measured starting from the throat (Fig. 1a), and the $x, y, r, \phi$ coordinates are determined as shown in Fig. 1b.

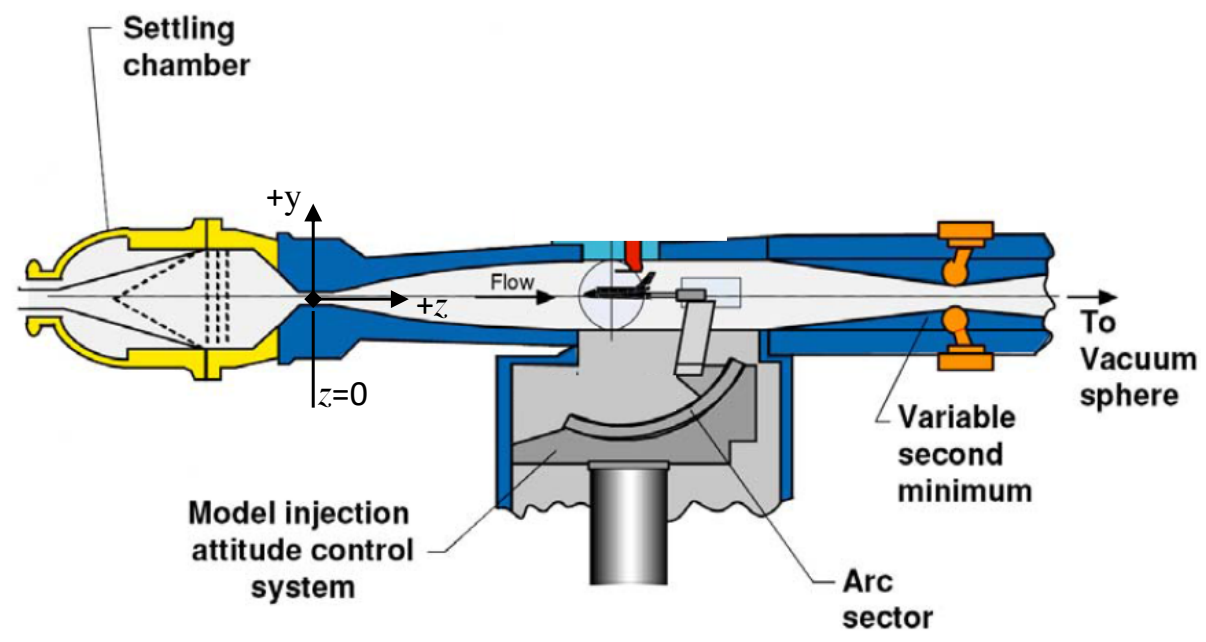

(a) Schematic of the 20-inch Mach 6 Tunnel.

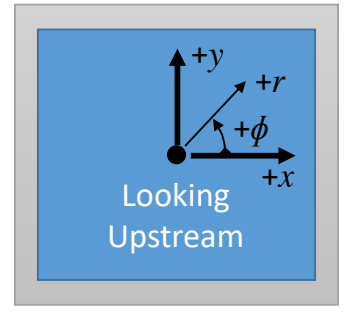

(b) Diagram of coordinate system used.

Figure 1: Schematic of the 20-inch Mach 6 Tunnel and relevant coordinate system for measurements.

\section{B. Instrumentation}

\section{Pressure Sensors}

Two types of pressure sensors were used to measure the freestream acoustic disturbance levels. PCB 132A31 transducers were used to measure pressure fluctuations between $11 \mathrm{kHz}$ and $1 \mathrm{MHz}$. These sensors were powered by the manufacturer's in-line signal conditioner, which provided a constant $4 \mathrm{~mA}$ current excitation to the built-in amplifier. The PCB output is high-pass filtered by built-in electronics and thus has a 3-dB cutoff at $11 \mathrm{kHz}$. The stated resonant frequency is above $1 \mathrm{MHz}$ and PCB sensors are reported to have a flat response to $300 \mathrm{kHz} .{ }^{14}$ Attempts to calibrate the sensors in a shock tube have been ongoing at Purdue University. ${ }^{15,16}$ No method of dynamic calibration was applied to the sensors shown in this paper, so the factory calibration was used. The PCB sensors were flush-mounted in a 6.35-mm-diameter stainless steel body that had a 3-degree taper on the front end of the probe.

The Kulite transducers were powered by an external signal conditioner that was capable of also amplifying and filtering the acquired signal. The sensors used in the measurements presented in this paper have a Bscreen to protect the sensing element from particle impacts. This screen limits the maximum frequency 
response of the sensors to approximately $20-50 \mathrm{kHz},{ }^{17}$ so they were used to measure disturbances in the 0-50 kHz range. A Kulite sensor with the B-screen cut off was used to show the difference in the change in frequency response for a limited number of measurements. Calibration of these sensors was conducted using a static sensitivity calibration method. These transducers were flush-mounted in a 2.26-mm-diameter stainless steel tube that then transitioned to a $6.35-\mathrm{mm}$ stainless steel probe body.

\section{Heat Transfer Sensors}

An atomic-layer thermopile (ALTP) probe was used to make measurements of freestream heat transfer. These sensors are a fairly new technology and have been used in previous studies of boundary-layer instabilities ${ }^{18,19}$ and stagnation point heating measurements. ${ }^{20}$ The ALTP sensor comes with an in-line amplifier that amplifies the AC signal of the sensor by a fixed gain of 5000. The gain for the DC signal of the sensor can be selected via a switch that amplifies the signal between 100 and 800 times. The AC signal read by the sensor was clipped by the amplifier due to large signal, so the results in this paper show the measurements obtained by bypassing the in-line AC amplifier. The bandwidth for these sensors is typically quoted as being up to $100 \mathrm{kHz}$ for the $\mathrm{DC}$ signal and $17 \mathrm{~Hz}-1 \mathrm{MHz}$ for the $\mathrm{AC}$ signal when using the in-line amplifier. Calibrations with a diode laser corroborated the approximate bandwidth. ${ }^{19}$ For this experiment, the ALTP sensor was mounted into a 7.94-mm-diameter body with a 3-degree taper to the front end of the probe. This sensor was mounted flush to the end of the probe tip.

\section{Hot-Wire Probes}

Wollaston wires with a $90 \%$ platinum- $10 \%$ rhodium core were soldered to hot-wire probes with prongs spaced $1.25 \mathrm{~mm}$ apart. Nitric acid was used to etch away the silver coating on the Wollaston wire until the 5-pm platinum-rhodium wire was exposed. The 5- $\mu \mathrm{m}$ wire was chosen to ensure that the Knudsen number of the wire $\left(K n=M / R e_{d} \sqrt{\gamma \pi / 2}\right)$ stayed in the continuum flow regime for the range of Reynolds numbers selected. The etched length of the wire varied from probe to probe, but was approximately 400-650 $\mathrm{\mu m}$ long. This yields a length-to-diameter ratio of between 80 and 130 for the sensing elements, so some end effects are possible for the lowest ratios. However, since the wires are etched, the heat conduction effects of the stubs should have less of an effect than if the bare sensing elements were directly mounted to the prongs.

A constant temperature anemometer (CTA) was used to make measurements of mass flux. The wires were driven to a nominal overheat ratio $\left(\tau=\left(T_{w}-\eta T_{0}\right) / T_{0}\right)$ of 0.9 to make the wire more sensitive to mass flux. The frequency response of the anemometer was checked with an injected square wave and showed that the system had a maximum bandwidth of up to approximately $130-150 \mathrm{kHz}$. The recovery factor of these wires $\left(\eta=T_{r} / T_{0}\right)$ was determined by measuring the cold-wire resistance of the probes at a nominal total temperature of $493.4 \mathrm{~K}$ for the range of Reynolds numbers. The recovery factor was determined to be approximately 0.87 . These wires were calibrated in situ when the wires survived through a full sweep of Reynolds numbers. The method of calibrating the hot wire was as described in Ref. 10, using a nonlinear least-squares fit to a modified King's law.

\section{Optical Measurement Techniques}

Two optical measurement techniques, focused-laser differential interferometry (FLDI) ${ }^{21,22}$ and high-speed schlieren, ${ }^{20}$ were used to complement measurements made with probes. In a novel arrangement, the two optical instruments were designed to be collinear and acquire data simultaneously with each other and with the probes in the tunnel. Results obtained with the collinear high-speed schlieren system are not shown in this paper, but will be described in a future paper.

A schematic of the FLDI is shown in Fig. 2. A single 300-mW, 532-nm laser with a Gaussian beam profile was used as the laser light source. The laser output was linearly polarized, with laser power controlled by rotating a half waveplate ahead of a polarizing beam splitter after the laser (not shown). Moving from left to right in Fig. 2, the laser beam is passed through a short-focus lens in order to expand the beam. After this lens, a half waveplate was used to rotate the plane of polarization to $45^{\circ}$ with respect to the vertical axis. A Wollaston prism on the transmitter side then split the vertical and horizontal components of polarization by 2 arc minutes. The transmitter-side field lens was placed one focal length away from the Wollaston prism. The field lens directed the optical axis of each of the beams to run parallel to each other through the test section with a spacing of approximately $180 \mu \mathrm{m}$ in the streamwise direction. The 


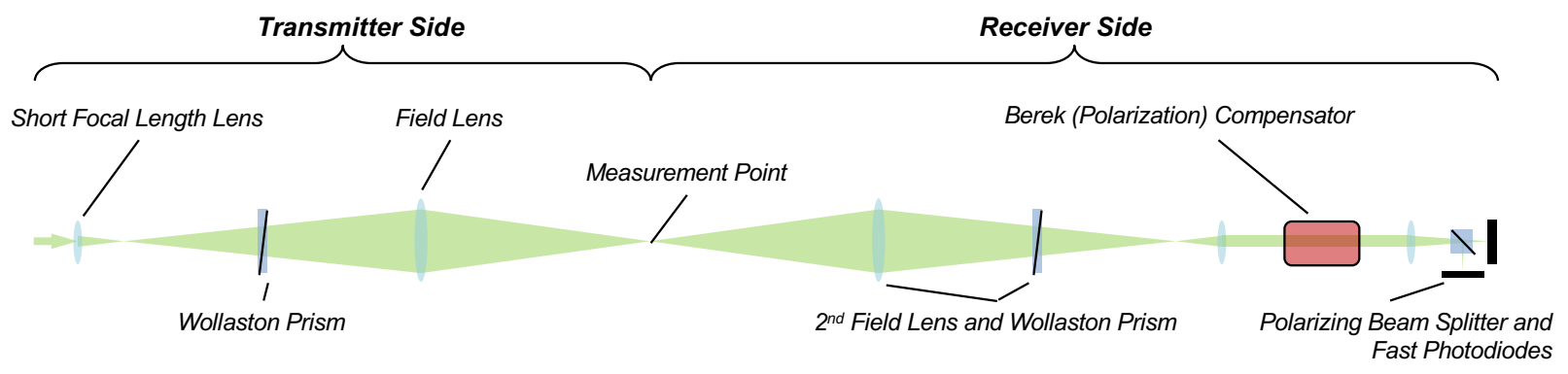

Figure 2: Schematic of light path of FLDI apparatus used to measure Mach-6 freestream density perturbations.

field lens also served to focus each of the orthogonally-polarized beams to two focal spots approximately 15-um in diameter. Temporal density fluctuations embedded in the freestream propagate through the beams and impart distinct but related optical phase shifts to each of the beams. The instrument is most sensitive to these fluctuations closest to the focal plane, which was approximately within $\pm 15 \mathrm{~mm}$ in the horizontal spanwise direction. Away from the focal region, the beam radius becomes large relative to the disturbance wavelength and the sensitivity of the FLDI is decreased. ${ }^{23}$

After the test section, the beams passed through a second field lens, which refocused the beams through a second Wollaston prism. This second Wollaston prism overlapped the orthogonally-polarized beams and then another short-focus lens collimated the beam. The polarization of the beam was adjusted to become circularly polarized with a Berek compensator. ${ }^{24}$ A polarizing beam splitter then directed each of the orthogonal components of the beam on to two different photodiode detectors. The amplitude modulations of the beam intensity measured by these photodiodes are related to the streamwise density fluctuations in the flow. Some initial data were taken with just the FLDI setup to ensure that the instrument was operating correctly (Fig. 2). When the FLDI technique appeared to work correctly, both FLDI and high-speed schlieren were operated simultaneously with their co-axial light paths for the last several days of the testing. Details on the collinear system is planned for a future paper.

\section{Other Instrumentation}

Two accelerometers with a bandwidth of $2 \mathrm{~Hz}$ to $10 \mathrm{kHz}$ were also mounted to the inside of one of the rake models to determine the vertical and lateral vibrations of the model. These were used to determine when the vibrations resulting from the model injection were sufficiently damped out before acquiring measurements. The total temperature in the rake was measured with a K-type thermocouple that was mounted in a singleshielded, vented probe. The mean total pressure was measured with a pitot tube attached to an absolute pressure transducer with a $103.4 \mathrm{kPa}$ range.

\section{Rake Models}

Two rake models were used to make measurements of the fluctuations of freestream properties in the 20-Inch Mach 6 Tunnel. A large rake with 21 possible sensor ports, measuring 254-mm wide, was used initially for simultaneous measurements of the freestream disturbances. The spacing between each possible sensor port is $11.18 \mathrm{~mm}$. The probes installed in this rake model included Kulite sensors with B-screens, PCB sensors, a single ALTP gauge outfitted with the in-line amplifier, and two hot-wire sensors.

Several measurements were made with this model in two different axial stations in the facility at different roll angles. The farthest upstream position was $z=2.149 \mathrm{~m}$ and the other position was $z=2.250 \mathrm{~m}$. The roll angle for this model was determined using the orientation of the leading edge relative to the floor of the tunnel. This model is approximately half of the width and height of the nozzle and all sensors were within the uniform core.

Due to the difficulty in replacing broken hot-wire sensors between runs, a smaller rake model was used for additional measurements. This rake model has only two sensor ports, and three different configurations were used during testing. These configurations were used to make measurements with two hot-wire sensors, an ALTP gauge, and a Kulite sensor with no screen. The spacing between the two sensors was $19.05 \mathrm{~mm}$. 
The smaller rake model was tested at a single axial station of $z=2.238 \mathrm{~m}$ and two roll angles: $0^{\circ}$ and $90^{\circ}$. The hot-wire sensors were tested at each roll angle and freestream unit Reynolds number. The ALTP gauge and the Kulite with no screen were only tested at a roll angle of $90^{\circ}$ for the same range of unit Reynolds numbers.

\section{Data Acquisition}

Mean data from the probes were low-pass filtered at $50 \mathrm{~Hz}$ and were acquired at a rate of $5 \mathrm{kHz}$. The total pressure and temperature from the pitot tube and thermocouple were acquired at a rate of $30 \mathrm{~Hz}$ using the system supplied by the facility. (More information on this system is presented in Ref. 13.) Dynamic probe data were AC-coupled and acquired at a rate of $2.5 \mathrm{MHz}$ for a duration of 3 seconds once the appropriate tunnel conditions had settled to a relatively steady state and a 2.5 -second wait time after the injected model reached the tunnel centerline. The accelerometers mounted in the rake showed that any vibration resulting from injecting the model sufficiently subsided after $1 \mathrm{~s}$, but the low-frequency AC-coupling at $0.159 \mathrm{~Hz}$ on the signal conditioning cards used for the Kulites required a longer wait time. The Kulite transducers were powered with a 10-V excitation and low-pass filtered with an 8-pole, 8-zero filter at a cutoff of $204.6 \mathrm{kHz}$. All other data from the PCB transducers, hot wires, ALTP gauge, and accelerometers were AC-coupled at $100 \mathrm{~Hz}$ and low-pass filtered with a low-pass 6-pole, 6-zero filter at a cutoff at $1 \mathrm{MHz}$. An additional 8-pole Butterworth filter with a low-pass cutoff frequency of $150 \mathrm{kHz}$ was applied to the hot-wire measurements in post-processing to reduce the effects of some of the extraneous electronic noise. This digital filter was only applied to the hot-wire data. The AC-coupling of the unsteady components of the signals was necessary to remove some of the dominating $60-\mathrm{Hz}$ electronic noise in the facility. Measurements from the photodiodes in the FLDI were acquired with a digital oscilloscope for the first $2 \mathrm{~s}$ at $10 \mathrm{MHz}$. No high-pass or low-pass filters were utilized in this preliminary demonstration of the FLDI to have the opportunity to observe the full dynamic range of the instrument, accepting the risk of aliasing. A summary of the data acquisition parameters is given in Table 1 .

Table 1: Summary of data acquisition parameters used.

\begin{tabular}{ccccc}
\hline Sensor & Coupling & Sampling Rate & High-Pass Cutoff & Low-Pass Cutoff \\
\hline \hline PCB (Pressure) & $\mathrm{AC}$ & $2.5 \mathrm{MHz}$ & $100 \mathrm{~Hz}$ & $1 \mathrm{MHz}$ \\
\hline Kulite (Pressure) & $\mathrm{AC}$ & $2.5 \mathrm{MHz}$ & $0.159 \mathrm{~Hz}$ & $204.6 \mathrm{kHz}$ \\
\hline Kulite (Pressure) & $\mathrm{DC}$ & $5 \mathrm{kHz}$ & - & $50 \mathrm{~Hz}$ \\
\hline ALTP (Heat Flux) & $\mathrm{AC}$ & $2.5 \mathrm{MHz}$ & $100 \mathrm{~Hz}$ & $1 \mathrm{MHz}$ \\
\hline ALTP (Heat Flux) & $\mathrm{DC}$ & $5 \mathrm{kHz}$ & - & $100 \mathrm{~Hz}$ \\
\hline Hot Wire (Mass Flux) & $\mathrm{AC}$ & $2.5 \mathrm{MHz}$ & & $1 \mathrm{MHz}($ analog) \\
& & & - & $150 \mathrm{kHz}($ digital) \\
\hline Hot Wire (Mass Flux) & $\mathrm{DC}$ & $5 \mathrm{kHz}$ & - & $50 \mathrm{~Hz}$ \\
\hline FLDI (Density) & $\mathrm{DC}$ & $10 \mathrm{MHz}$ & - & - \\
\hline Total Temperature (Facility) & $\mathrm{DC}$ & $30 \mathrm{~Hz}$ & - & - \\
\hline Total Pressure (Facility) & $\mathrm{DC}$ & $30 \mathrm{~Hz}$ & & \\
\hline
\end{tabular}

\section{Analysis}

\section{A. Power Spectrum Estimation and RMS Calculations}

The power spectral density for each sensor are estimated with Welch's method. Hamming windows of $2^{14}$ points and $50 \%$ overlap are averaged to determine the power spectral density. These parameters yield a frequency resolution of $152.6 \mathrm{~Hz}$. Previous work by Rufer and Berridge ${ }^{12}$ was integrated out to $100 \mathrm{kHz}$, so the RMS values for total pressure in this paper are likewise integrated out to $100 \mathrm{kHz}$. Similarly, hot-wire measurements by Chokani et al. ${ }^{11}$ used a bandwidth of $40 \mathrm{kHz}$, so the RMS values for mass flux fluctuations will use similar bandwidths for direct comparison to data. It was unclear what bandwidth was used to find the RMS of the measurements made by Stainback and Kubendran, ${ }^{4}$ so the present measurements were 
integrated to a bandwidth of $100 \mathrm{kHz}$ for comparison to these data.

Much of the data were affected by electronic noise. The power spectra in Fig. 3 are from measurements made by a hot wire sitting at ambient conditions in a sealed test section. No digital filtering was applied to these data. The blue trace shows the baseline noise floor of the hot-wire anemometer, with the $f^{2}$-noise starting near $2 \mathrm{kHz}$, and extending to approximately $50 \mathrm{kHz}$. The roll-off near $100 \mathrm{kHz}$ and beyond is a result of the tuning of the wire and the low-pass filter of the analog signal conditioner. The orange trace shows the electronic noise floor when the servo motors for the model injection system are energized. Tonal spikes are visible in the spectra between $2 \mathrm{kHz}$ and $1 \mathrm{MHz}$ when this occurs. The yellow trace shows the electronic noise floor when the electric heaters for the facility are turned on, no flow passes through the tunnel, and the servo motors are not energized. This trace is characterized by an increase in the low-frequency range between $100 \mathrm{~Hz}$ and $2 \mathrm{kHz}$.

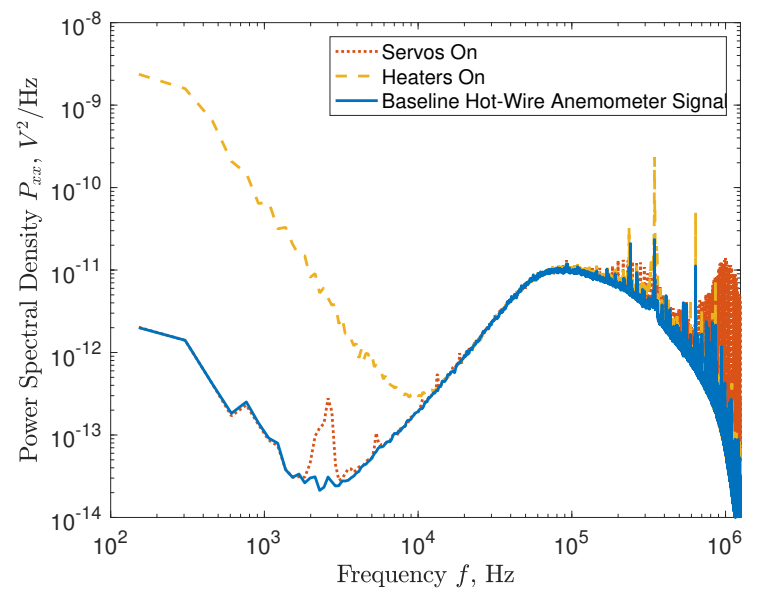

Figure 3: Example of electronic noise measured by a hot wire. No flow.

Due to the high levels of electronic noise in the facility, some post-processing was applied to the power spectra to reduce the appearance of tonal spikes in the spectra. To obtain an estimate of the power spectra that was unaffected by electronic noise, the incoherent spectra $\left(1-\gamma^{2}\right) P_{x x}$ were used, where $P_{x x}$ is the power spectral density. ${ }^{25}$ An example of the improvements possible are given in Fig. 4 . The blue line is the power spectral density for a PCB sensor at a low Reynolds number. It is marked by large-amplitude tonal spikes, which were later determined to be a result of the electronic noise generated by the servo motors of the model-injection system. The red line is the resultant incoherent spectrum for the same PCB sensor. The differences between the two traces show a reduction in the high-frequency noise peaks.

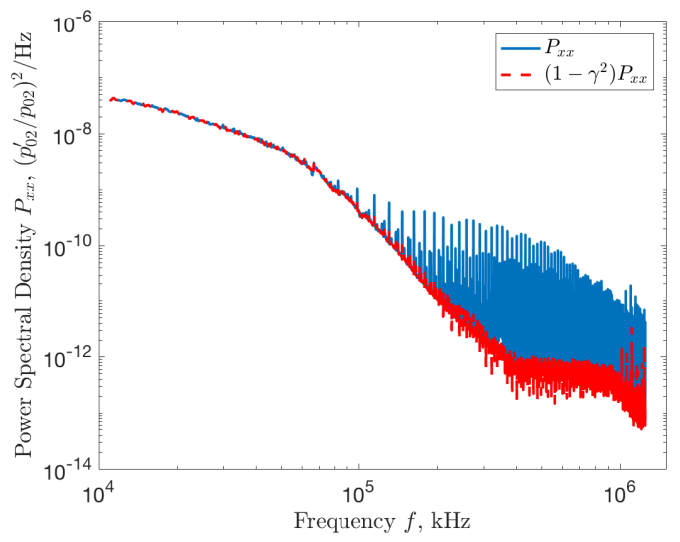

Figure 4: Power spectra and incoherence spectra for pressure sensor located at $z=2.250 \mathrm{~m}, \phi=-90^{\circ}$, $\bar{R} e=3.37 \times 10^{6} / \mathrm{m}$. 


\section{B. Analysis of the FLDI Measurements}

For the FLDI, the two digital signals from the photodiodes are subtracted in post processing to obtain the phase difference in the signals from each of the FLDI beams. The raw signals from the FLDI beams are sensitive to density gradient, but can be easily related to the fluctuating component of density using Eq. 3.55 from Ref. 24. The fast Fourier transform (FFT) of this quantity is computed using Welch's method with a $2^{16}$-point (0.0066 s) Hanning window with $50 \%$ overlap. This yields a frequency spacing of $152.6 \mathrm{~Hz}$ to be consistent with the other power spectra.

The absolute sensitivity of this instrument has not yet been determined, so these spectra are given in arbitrary units. These spectra also have not been normalized for the instrument responsivity in frequency. However, that response can be estimated using methods outlined in Refs. 23, 24,26. The calculation is a convolution of three different effects: streamwise beam separation (Eq. 3.35 of Ref. 24), beam spot size with an infinitesimally thin disturbance in the spanwise direction at the focal plane (Eq. 3.42 of Ref. 24), or beam spot size with a finite width disturbance field in the spanwise direction centered on the focal plane (Eq. 3.43 of Ref. 24). The assumption of an infinitesimally thin disturbance field is a best-case scenario for instrument responsivity. The assumption of a disturbance field width equal to that of the tunnel test section (508 $\mathrm{mm}$ ) is a worst-case scenario for instrument responsivity. The $-3 \mathrm{~dB}$ high-frequency roll-offs for the best- and worst-case scenarios are $2.32 \mathrm{MHz}$ and $161 \mathrm{kHz}$, respectively, for a freestream velocity of approximately $930 \mathrm{~m} / \mathrm{s}$. Future studies must be performed to better understand the influence of the finite-width of the disturbance field on instrument response.

\section{Determining Propagation Angles and Speeds of Disturbances}

A disturbance speed and disturbance propagation angle can be determined using the knowledge of the spacing of the probes $(\Delta r)$ and the time delay with which the two probes sense a particular disturbance $(\Delta t)$. The spacing of the probes is known, but the time delay must be determined through spectral analysis of the signals measured by the two probes. The time delay of the disturbance measured by the two probes can be determined from the coherence and the difference of the phase of the cross-spectra. Using the geometry illustrated in Fig. 5, the disturbance convection speed $\left(u_{c}\right)$ and disturbance angle $(\mu)$ are a measure of the speed and angle of the Mach wave generated by a dominant disturbance or eddy in the nozzle-wall boundary layer. This wave will pass over sensors 1 and 2 as it convects downstream at speed $u_{c}$, where $u_{c} / u_{\infty}<1$. From the parameters illustrated in Fig. 5 and defined above, the rate at which the Mach wave passes between the two sensors can be defined as

$$
u_{r}=\frac{\Delta r}{\Delta t}
$$

which is a non-physical "speed" at which information travels perpendicular to the dominant convection speed. The dominant convection speed is defined as

$$
u_{c}=\frac{\Delta x}{\Delta t}
$$

where $\Delta x$ is the distance of the wave from sensor 1 when it is first detected by sensor 2, as depicted in Fig. 5 .

Assuming that the signal measured comes from a right-travelling wave, as shown in Fig. 5 , it has the form $A e^{-\omega t+k x_{\perp}}$. Thus, the phase of the signals measured by the sensors can be defined as $\Psi=\omega t-k x_{\perp}$. To determine the time delay between the measurement of the same wave by sensor 1 and sensor 2, the difference in the phases is examined:

$$
\begin{aligned}
\Delta \Psi=\Psi_{2}-\Psi_{1} & =\omega t_{1}-k x_{\perp}-\left(\omega t_{2}-k x_{\perp}\right) \\
\Delta \Psi & =\omega \Delta t=2 \pi f \Delta t
\end{aligned}
$$

where $\omega$ is the angular frequency of the propagating wavefront, $x_{\perp}$ is the direction normal to the wave, and $k$ is the wave number of the propagating wavefront. The coherence is first computed to determine if a linear relationship exists between the signals measured by adjacent sensors 1 and 2 . If a linear relationship exists, the frequency at the peak of the coherence function $\gamma^{2}$ is determined and the resulting phase difference is obtained from the phase of the cross-spectrum $P_{x y}$.

The definition of the angle of the disturbance relative to the freestream direction can be given through the definition of a Mach angle

$$
\sin \mu=\frac{1}{M_{c}}=\frac{a_{\infty}}{u_{\infty}-u_{c}}
$$




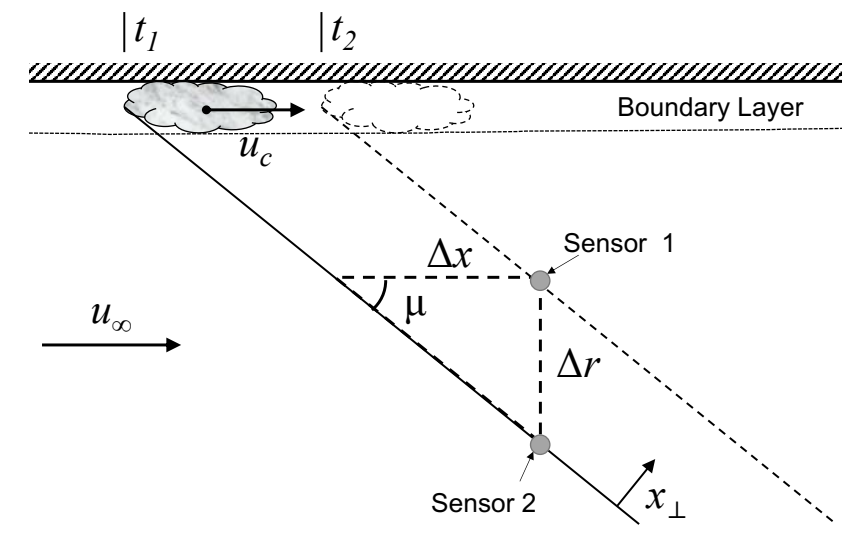

Figure 5: Schematic diagram of disturbance propagation angles relative to sensor positioning.

where $a_{\infty}$ is the definition of the speed of sound in the freestream. The Mach angle can also be found using geometry:

$$
\tan \mu=\frac{\Delta r}{\Delta x}=\frac{\Delta r}{u_{c} \Delta t} .
$$

Eq. 5 and 6 can be combined using simple trigonometric properties to give a quadratic equation of the form

$$
A u_{c}^{2}+B u_{c}+C=0
$$

where

$$
\begin{gathered}
A=\left(\frac{\Delta t}{\Delta r}\right)^{2}-\frac{1}{a_{\infty}^{2}} \\
B=2 \frac{u_{\infty}}{a_{\infty}^{2}} \\
C=1-M_{\infty}^{2}
\end{gathered}
$$

Solving for $u_{c}$ provides two solutions, one for $u_{c}>u_{\infty}$ and one for $u_{c}<u_{\infty}$. The physically relevant $u_{c}$ must be the solution that is less than $u_{\infty}$.

An example of a comparison between two sensors is given in Fig. 6 . Figure 6 a shows a coherence of almost unity between two Kulite sensors at $f<400 \mathrm{~Hz}$ and $f>75 \mathrm{kHz}$. The coherence in this range of frequencies is dominated by noise, both from the electric heaters for the facility and the servo motors for the model injection system. Between $400 \mathrm{~Hz}$ and $10 \mathrm{kHz}$, a small peak is visible in the coherence of the two Kulite sensors in Fig. 6a, with a local maximum at approximately $2 \mathrm{kHz}$. Background uncorrelated noise causes the coherence to be small. For reference, Laufer also noted a small correlation coefficient when examining the cross-correlation between two hot wires in the freestream of a supersonic tunnel. ${ }^{27,28}$ These disturbances are essentially the Mach waves from turbulent eddies in the boundary layer. Figure $6 \mathrm{~b}$ shows no coherence between the two PCB sensors at the same frequencies, which is expected, considering that the lower limit of the frequency response of the sensor is approximately $11 \mathrm{kHz} .{ }^{14}$ Taking the phase of the cross-spectra between two sensors shows the difference in phase between the measurements made by the sensors (Fig. 7).

The peak in the coherence in Fig. 6a occurs at $f=2136 \mathrm{~Hz}$, where the phase difference shown in Fig. 7 is 0.554 radians. Using Eq. 4, the time difference between when each sensor measures the dominant disturbance in the flow is approximately $41 \mu \mathrm{s}$. Using Eqs. 7-10 yields a convection velocity of $u_{c}=0.70 u_{\infty}$. The angle of the disturbance is found using Eq. 5, and for this case, is approximately $30^{\circ}$. Due to the spectral noise in the coherence and the cross-spectra, a Gaussian fit to the points between $900 \mathrm{~Hz}$ and $4 \mathrm{kHz}$ will be used to approximate the peak in the coherence. A linear fit to the phase of the cross spectra in the same frequency range will be used to determine the phase difference corresponding to the peak. 


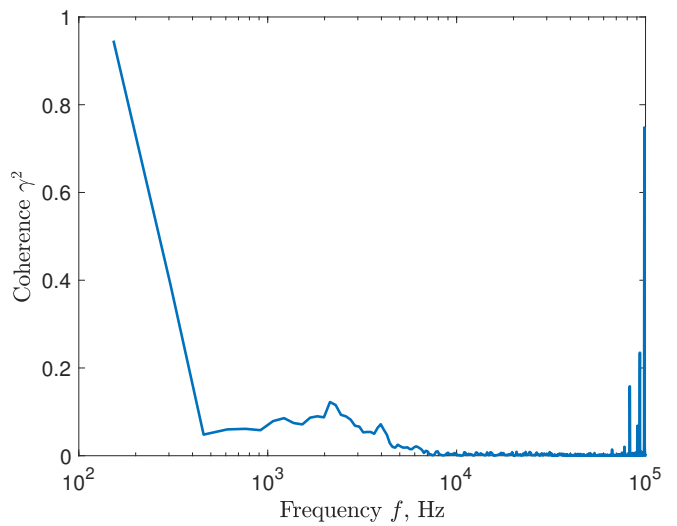

(a) Kulites located at $r=68.07 \mathrm{~mm}$ and $90.42 \mathrm{~mm}$.

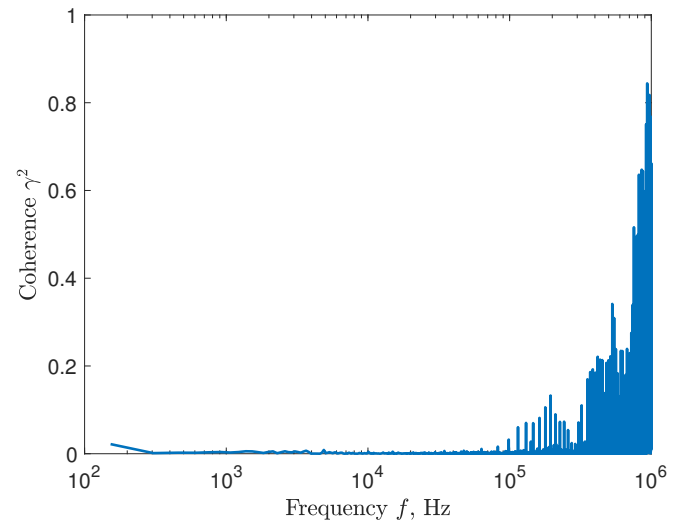

(b) PCBs located at $r=0 \mathrm{~mm}$ and $-90.42 \mathrm{~mm}$.

Figure 6: Magnitude-squared coherence for pressure sensors located at $z=2.250 \mathrm{~m}, \phi=-90^{\circ}$. $\overline{R e}=$ $26.3 \times 10^{6} / \mathrm{m}$.

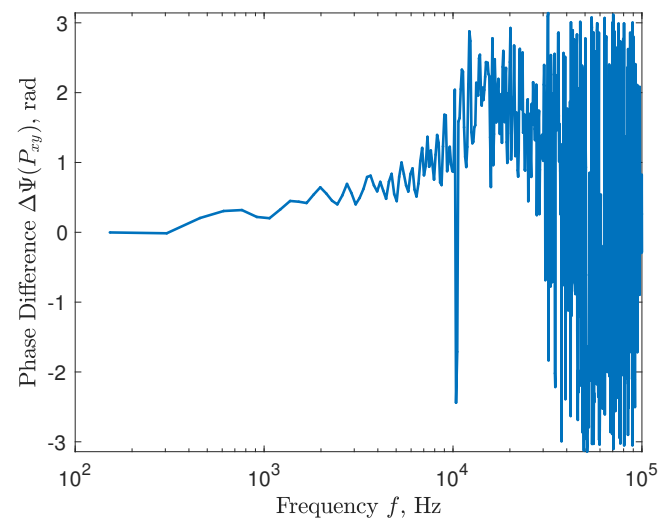

Figure 7: Phase lags between measurements in pressure sensors located at $z=2.250 \mathrm{~m}, \phi=-90^{\circ}$. $\bar{R} e=26.3 \times 10^{6} / \mathrm{m}$.

\section{Results}

\section{A. Pressure Fluctuations}

The power spectra for multiple Reynolds numbers measured by the Kulite sensors is shown in Fig. 8. These plots of the power spectral density show that the measurements are relatively similar at each location shown here, except at the lowest unit Reynolds number. At the lowest unit Reynolds number tested, the amplitude of the measured signal is higher between $0-40 \mathrm{kHz}$.

Figure 9 shows that there is good symmetry across the span of the measurement region. For the highest and the lowest Reynolds numbers tested, the spectra agree very well when the rake was rotated to $\phi=0^{\circ}$, $+90^{\circ}$, and $-90^{\circ}$. This was expected based on previous measurements by Rufer and Berridge, ${ }^{12}$ although the present measurements were made at a location farther upstream than their measurements. Previous tunnel calibrations by Rhode and DeLoach suggest uniformity in the mean flow in these particular measurement stations in the facility as well. ${ }^{29}$ The rake is not wide enough to measure outside the uniform core flow of the facility, so it is not surprising that the unsteady pressure measurements in this region are fairly uniform.

Figure 9 shows that the PCB transducers agree with the Kulite transducers fairly well in the range of 11-40 kHz. However, the measurements made at the lowest unit Reynolds number of $3.31 \times 10^{6} / \mathrm{m}$ agree for a much smaller range of only 11-20 kHz. Work done at AEDC's Hypervelocity Wind Tunnel 9 showed that the region of overlap in these spectra can be used to scale the calibration of the PCB sensor. ${ }^{30}$ Therefore, a 


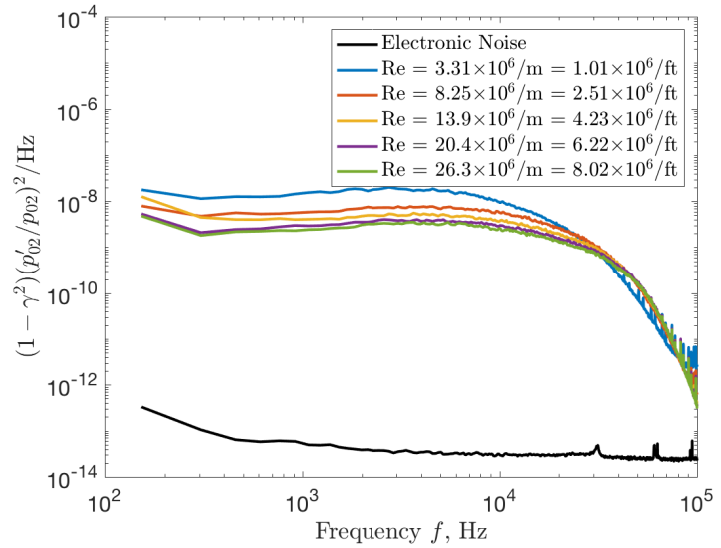

(a) $68.1 \mathrm{~mm}$ from centerline, $\phi=0^{\circ}$.

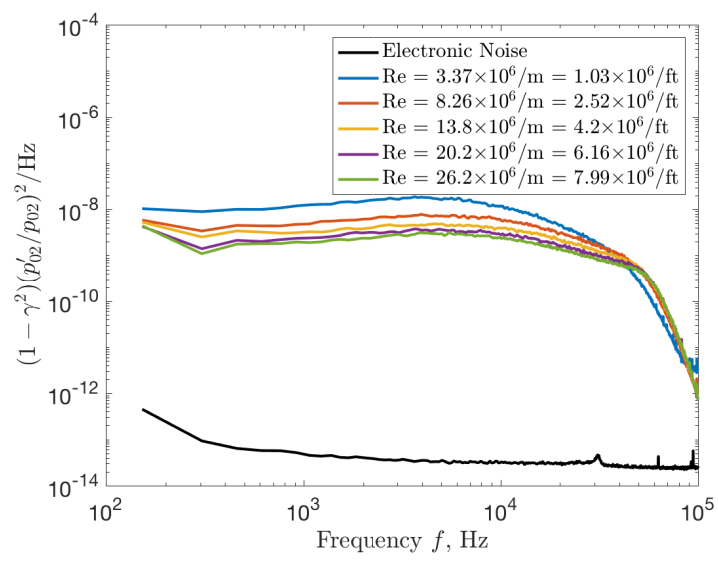

(c) $68.1 \mathrm{~mm}$ from centerline, $\phi=-90^{\circ}$.

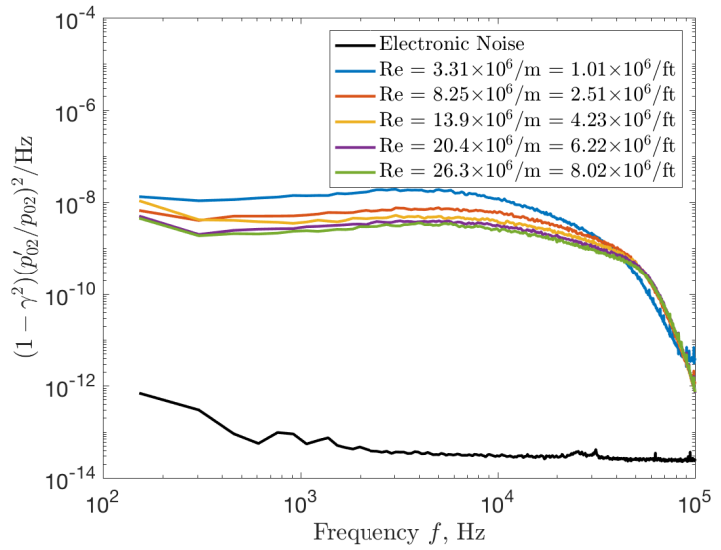

(b) $90.4 \mathrm{~mm}$ from centerline, $\phi=0^{\circ}$.

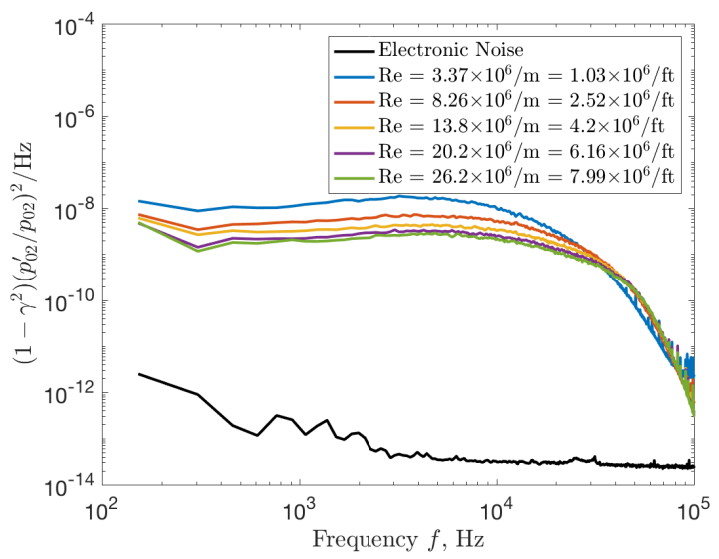

(d) $90.4 \mathrm{~mm}$ from centerline, $\phi=-90^{\circ}$.

Figure 8: Power spectra of measurements from the Kulite sensors with B-screens in the large rake positioned at $z=2.149 \mathrm{~m}$.

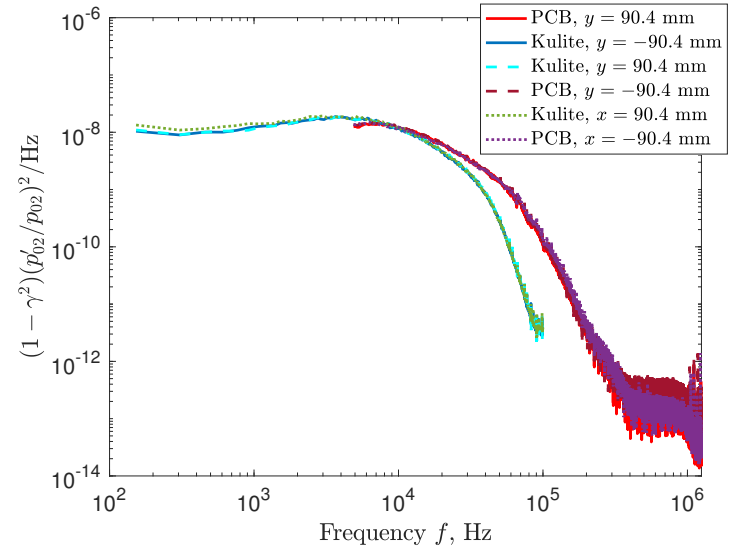

(a) $\overline{R e}=3.31 \times 10^{6} / \mathrm{m}$.

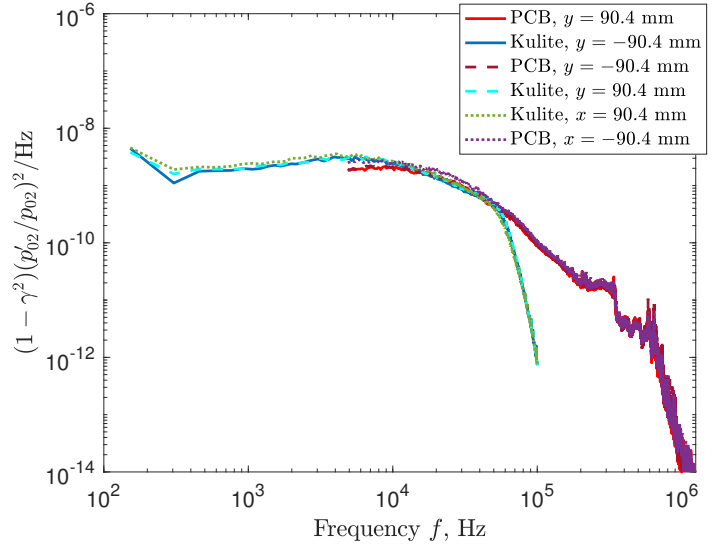

(b) $\bar{R} e=26.3 \times 10^{6} / \mathrm{m}$.

Figure 9: Power spectra showing agreement across the span of the facility at $z=2.149 \mathrm{~m}$. 
combination of Kulite and PCB sensors can then be used to estimate the noise from 0-1 MHz. This method assumes that the frequency response in the overlapping range is similar, which may not always be the case. For low Reynolds numbers, as in Fig. 9a, the signal of the Kulite and PCB in the 11-40 kHz range does not agree as well, so this method of adjusting the calibration may not be applicable. No calibration matching between the Kulite and PCB was attempted for the data here; in this instance, the factory calibration for the PCB happens to agree well with the Kulite calibration.

Previous measurements in Ref. 12 indicate that the acoustic noise in the span of the tunnel should be fairly uniform. Figure 10 shows a discrepancy between the PCB sensor located on the centerline of the tunnel and the PCB sensor located at a location of $90.4 \mathrm{~mm}$ from the centerline. The spectra of the PCB measurements for the lowest Reynolds number tested is shown in Fig. 10a and for the highest Reynolds number tested is shown in Fig. 10b. The spectra for the different Reynolds numbers in between look fairly similar to the spectra in Fig. 10b. There is good agreement in the spectra for the three different angular positions of the rake when comparing a single sensor to itself. However, the magnitude of the pressure fluctuation levels for the PCB transducer located on the centerline appears to have a lower amplitude than the other pressure transducers. The discrepancy in the amplitude may be due to the usage of the factory calibration for the PCB transducer in question. Other groups have seen that the factory calibration for the PCB transducers can have an error as high as 30-50\%. ${ }^{15,30}$ Unfortunately, the centerline transducer was never swapped with another so this was not verified during the test.

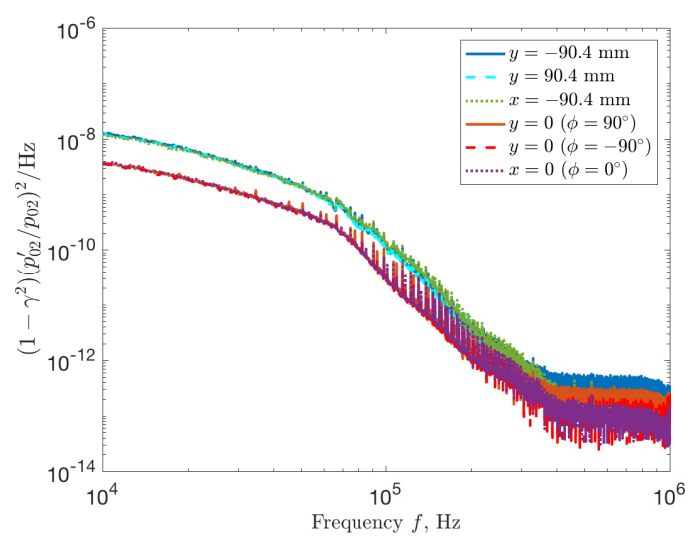

(a) $\overline{R e}=3.31 \times 10^{6} / \mathrm{m}$.

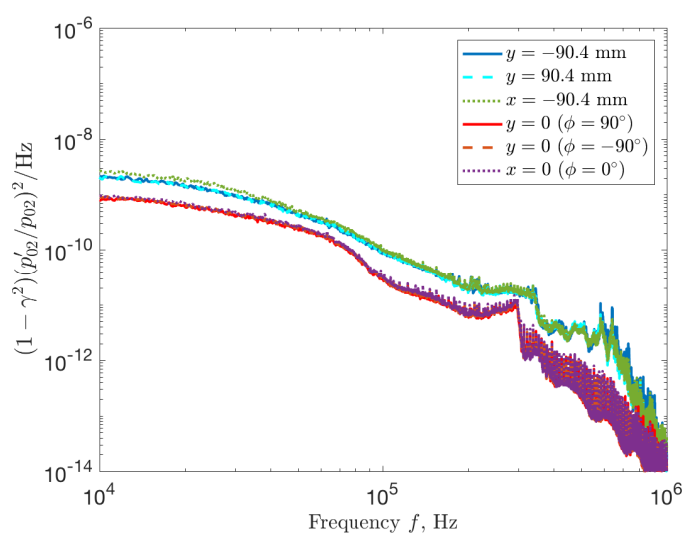

(b) $\bar{R} e=26.3 \times 10^{6} / \mathrm{m}$.

Figure 10: Power spectra showing PCB measurements across the span of the facility at $z=2.149 \mathrm{~m}$.

Work is ongoing at Purdue University to calibrate the transducers used in this experiment. Using a small shock tube (ST), the PCB sensors were calibrated by varying shock strengths to determine a sensitivity of the sensors. The effect of a preliminary calibration for the PCB sensors on the spectra is given in Fig. 11. The thin solid lines in Fig. 11 are spectra of the Kulite measurements taken at $y=-90.4 \mathrm{~mm}$, truncated at $100 \mathrm{kHz}$. The dashed lines are the spectra of the PCB measurements using the factory calibration, while the thick solid lines are the spectra of the PCB measurements using the shock tube calibration. The shock tube calibration appears to improve the measurements made by the PCB sensor at $y=0$ based on the agreement with the Kulite measurements in the 11-40 kHz spectral band. However, the shock tube calibration appears to cause the PCB sensor at $y=90.4 \mathrm{~mm}$ to disagree with the Kulite measurements in the same band. The cause of this discrepancy is unknown and more work is underway to determine the cause.

A limited number of measurements were made with a Kulite where the B-screen was removed. The power spectra of the measurements made with this sensor are given in Fig. 12. These spectra show information similar to Fig. 8, except that the frequency response of the sensor has increased out to approximately $100 \mathrm{kHz}$. When the B-screen was removed, a small lip around the diaphragm of the sensor was left, creating a cavity. A small peak is seen in the spectra near $100 \mathrm{kHz}$, which is within the range of possible organ-pipe frequencies of the cavity around the sensing element. 


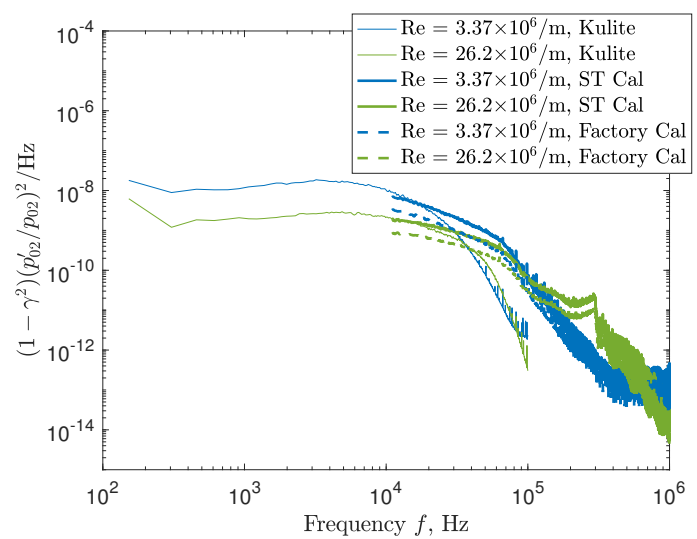

(a) $y=0$.

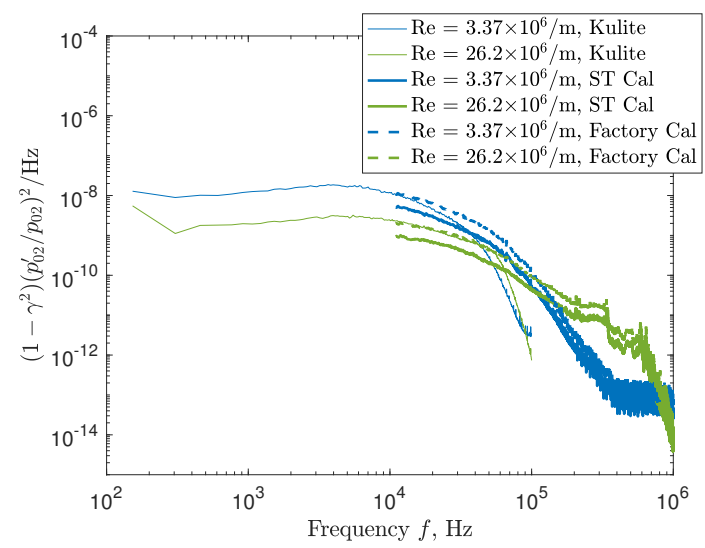

(b) $y=90.4 \mathrm{~mm}$.

Figure 11: Power spectra showing comparison of calibrations for PCB sensors at $z=2.149 \mathrm{~m}$.

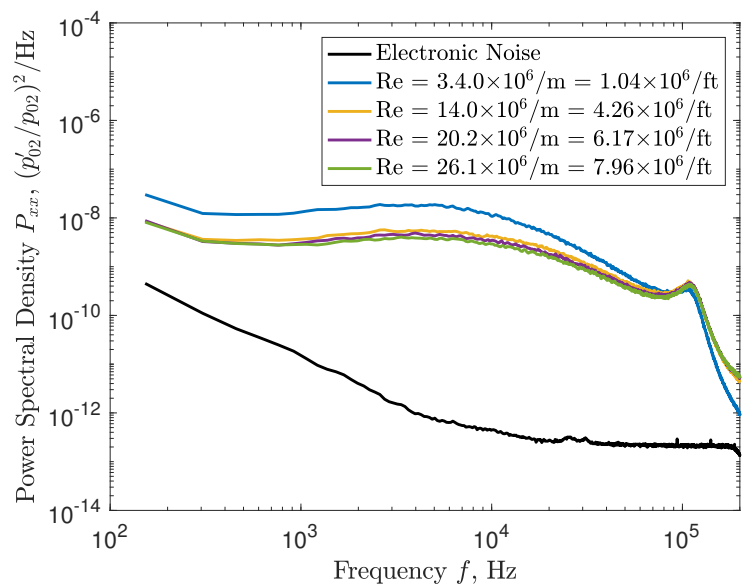

Figure 12: Power spectra showing measurements of a Kulite without a screen: $z=2.238 \mathrm{~m}, y=9.53 \mathrm{~mm}$.

\section{RMS Measurements}

A comparison of the RMS pressure fluctuations up to $100 \mathrm{kHz}$ is presented in Fig. 13, using the factory calibrations for the PCB sensors. The measurements from the present experiment agree fairly well with the data from Ref. 12, except for the RMS amplitudes given by the PCB located on the centerline. As shown in Figs. 10 and 11, this is possibly due to an error in the factory calibration. Application of the shock tube calibration simply causes the RMS values of the centerline PCB measurements to agree better with the other data. However, the shock tube calibration for the PCB sensor at $r=90.4 \mathrm{~mm}$ causes the RMS values of those measurements to decrease to approximately 1\%. This decrease in RMS would yield results similar to those currently given in Fig. 13.

Because the frequency response of the $\mathrm{PCB}$ is limited to a range of $11 \mathrm{kHz}-1 \mathrm{MHz}$, the computation of the RMS fluctuations measured by the PCB sensors may differ from those of the Kulite transducers. The bandlimited RMS fluctuations measured by both the Kulite transducers and the PCB sensors from $11-50 \mathrm{kHz}$ contributes approximately $53-70 \%$ of the RMS fluctuations measured by the Kulites and approximately $73-$ $77 \%$ of the RMS fluctuations measured by the PCBs. Thus, the difference in bandwidth of the two sensors happens to affect the calculation of the RMS fluctuations very little. 


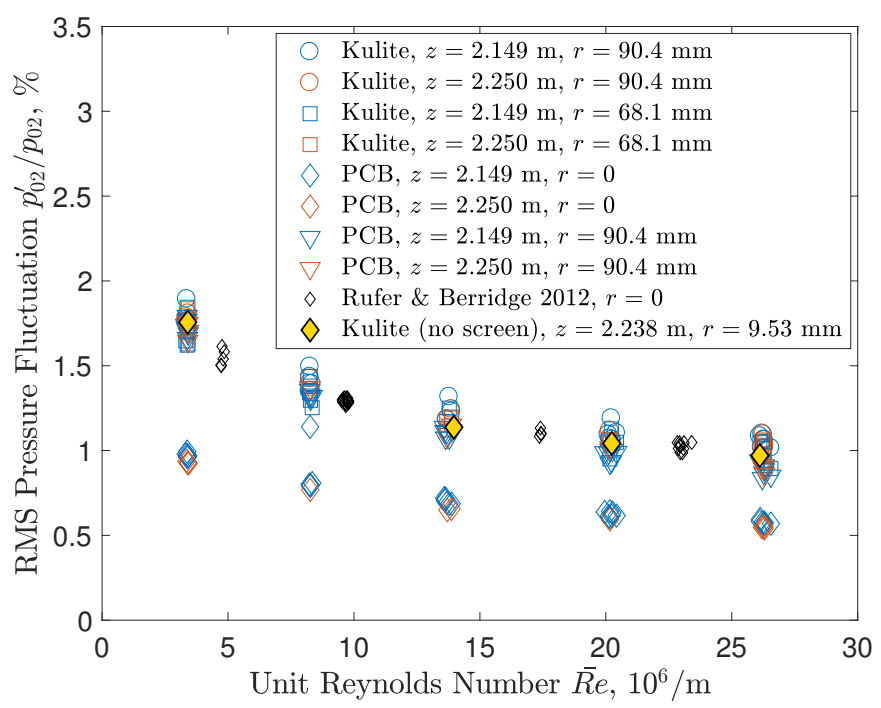

Figure 13: RMS amplitude of freestream pressure fluctuations up to $100 \mathrm{kHz}$

\section{Disturbance Angles}

Since multiple Kulite and PCB sensors were used to make measurements of the freestream, an attempt to find disturbance propagation angles and propagation speeds was made. The Kulite sensors were located at $r$ $=68.07 \mathrm{~mm}$ and $90.42 \mathrm{~mm}$ and the PCB sensors were located at $r=0 \mathrm{~mm}$ and $-90.42 \mathrm{~mm}$ on the 10-inch rake. Figure 14 shows the coherence and phase differences between two Kulites for a sweep of Reynolds numbers. Almost no coherence was seen in the PCBs, aside from the coherence of the electronic noise measured by both sensors, as in Fig. 6b. Thus, no data from the PCB sensors are shown.

The electronic noise between $f<400 \mathrm{~Hz}$ and $f>60 \mathrm{kHz}$ has a coherence of nearly $\gamma^{2}=1$, so only data between $300 \mathrm{~Hz}$ and $10 \mathrm{kHz}$ are shown in Fig. 14a. In Fig. 14a, a small broad peak in the coherence is centered at approximately $2000 \mathrm{~Hz}$ for the range of Reynolds numbers. This peak does not shift much, but grows slightly in amplitude as the Reynolds number increases. The coherence at the highest Reynolds number is still relatively low, at approximately $\gamma^{2}=0.1$. The lower two Reynolds numbers have almost no peak in the coherence, possibly because the boundary layer on the nozzle wall is only transitional or in the early stages of turbulence. The coherence of these measurements could be increased if measurements were made closer to the nozzle walls or if the data acquisition time was increased.

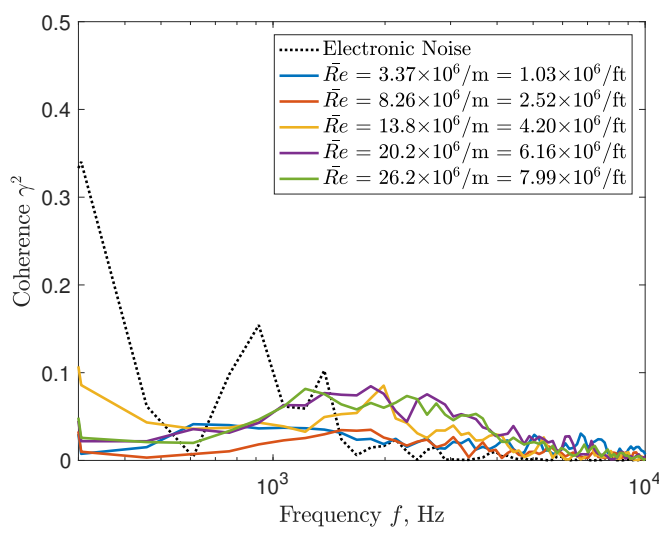

(a) Coherence between Kulites.

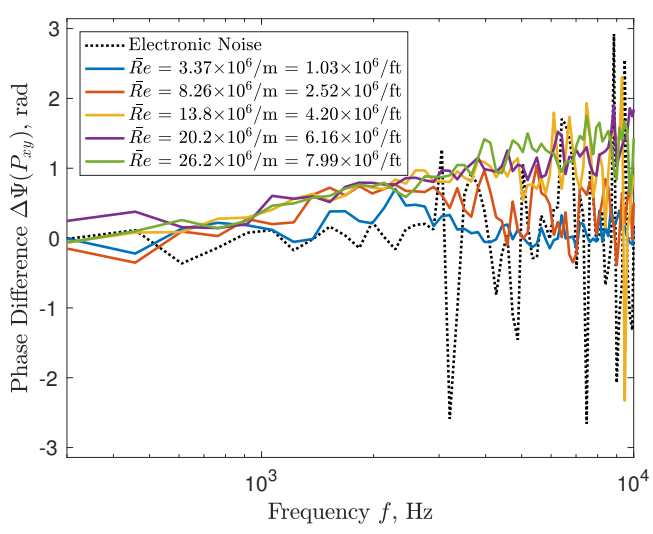

(b) Phase lags between Kulites.

Figure 14: Coherence and phase differences between two Kulites at $z=2.250 \mathrm{~m}, \phi=-90^{\circ}$. 
Using the phase differences of the measurements (Fig. 14b) at the local peak frequency of the coherence and the separation distance between the probes, the propagation speed and angle can be determined for the measurements made, as in Section III.C. A compilation of the disturbance speed and angle as measured by the two Kulite transducers for each of the conditions is given in Figs. 15 and 16, respectively. In these figures, the red symbols indicate measurements made at $z=2.250 \mathrm{~m}$. The blue symbols indicate the measurements made at $z=2.149 \mathrm{~m}$, the farthest forward station.

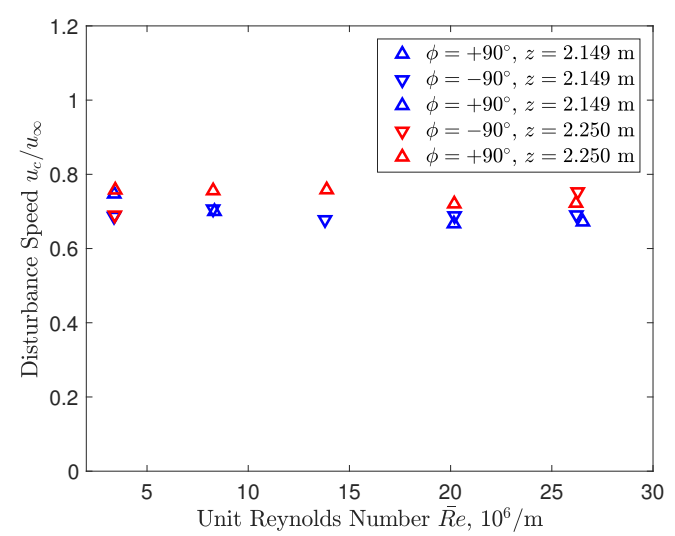

(a) Measurements toward contoured walls $\left(\phi= \pm 90^{\circ}\right)$.

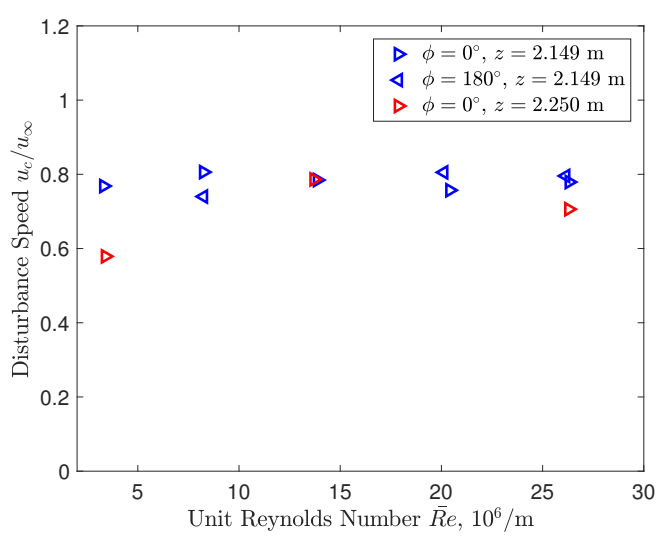

(b) Measurements toward flat sidewalls $\left(\phi=0^{\circ}, 180^{\circ}\right)$.

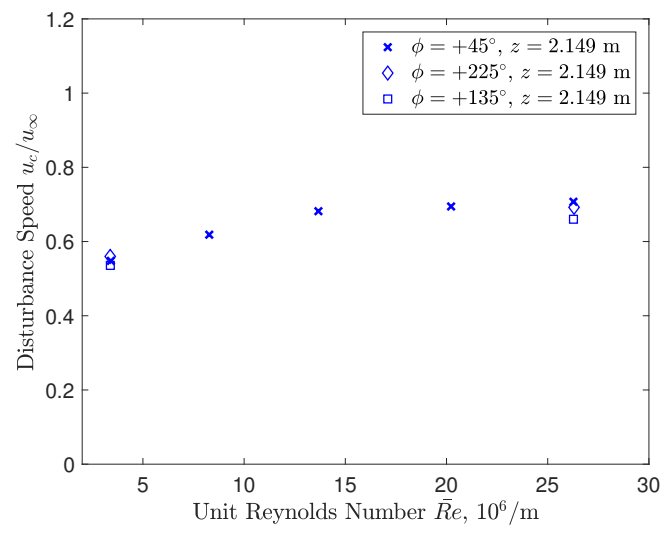

(c) Measurements toward corners $\left(\phi=45^{\circ}, 135^{\circ}, 225^{\circ}\right)$.

Figure 15: Propagation speed of the disturbances emanating from the nozzle walls.

In each of Figs. 15 and 16, the plots are organized to show measurements corresponding to the location of the two Kulite probes in the two-dimensional nozzle. Figs. 15a and 16a show the data for the rake oriented at $\phi= \pm 90^{\circ}$, so that the Kulite probes were closer to either the top or bottom contoured walls. Figs. 15b and 16b show the data for the rake oriented at $\phi=0^{\circ}$ or $180^{\circ}$, so that the Kulite probes were closer to the flat sidewalls. Figs. $15 \mathrm{c}$ and $16 \mathrm{c}$ show the data for the rake oriented at $\phi=45^{\circ}, 135^{\circ}$, and $225^{\circ}$, so that the rake was at a diagonal and the Kulite probes were closer to the corners of the nozzle. Data were only acquired at the $z=2.149-\mathrm{m}$ station in the facility for this last set of roll angles.

At the lowest unit Reynolds number of $3.40 \times 10^{6} / \mathrm{m}$, the spread of different disturbance speeds ranges from $53-77 \%$ of the freestream speed and the angles ranges from approximately $23^{\circ}-47^{\circ}$ for all of the different orientations of the rake. This may be because the nozzle wall boundary layers are not fully turbulent, so the turbulent eddies are still fairly intermittent. As mentioned previously, the coherence for many of the Kulite measurements at the lowest unit Reynolds number is closer to $\gamma^{2}=0.02-0.05$, less than half of the coherence at the highest unit Reynolds number tested. The low coherence in these measurements may result in an increase in uncertainty of these derived quantities.

Data when the Kulites were closer to the flat sidewalls also appear to have a larger uncertainty than when measurements were taken near the contoured walls or on the diagonal. The speed of propagation for 


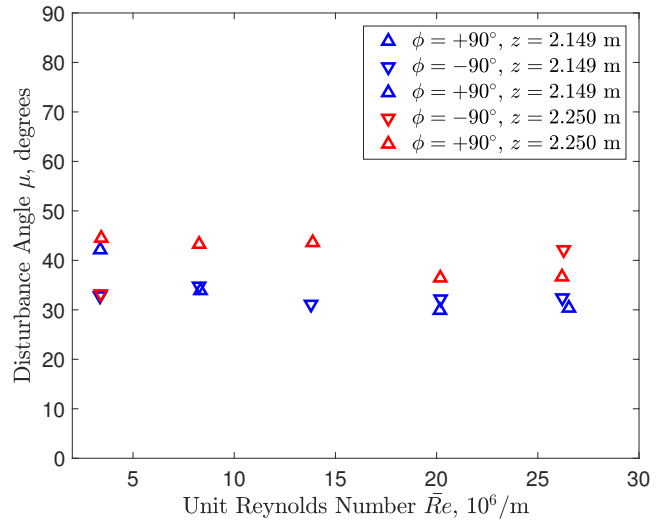

(a) Measurements toward contoured walls $\left(\phi= \pm 90^{\circ}\right)$.

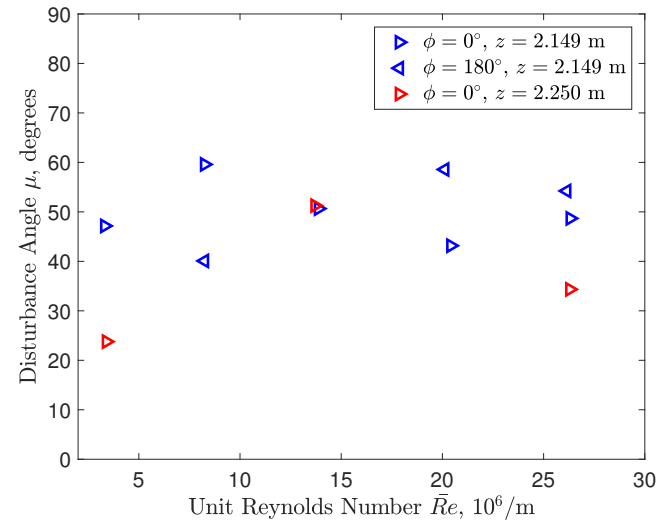

(b) Measurements toward flat sidewalls $\left(\phi=0^{\circ}, 180^{\circ}\right)$.

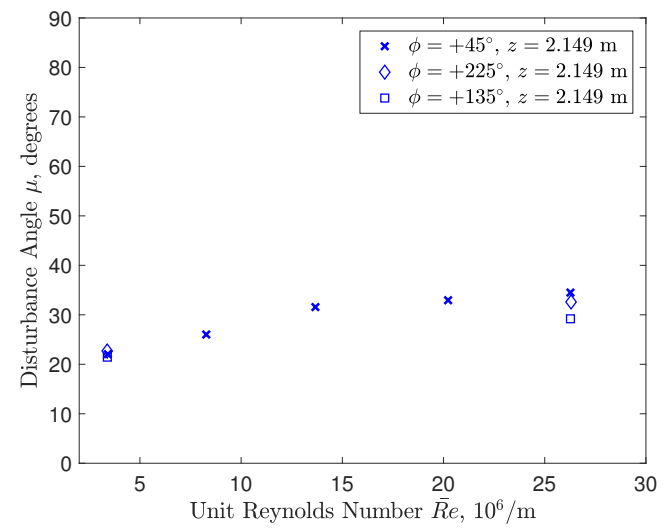

(c) Measurements toward corners $\left(\phi=45^{\circ}, 135^{\circ}, 225^{\circ}\right)$.

Figure 16: Angles of disturbances emanating from the nozzle walls.

disturbances emanating from the flat sidewalls appears to be on the order of $58-81 \%$ of the freestream speed. The angle of propagation for disturbances emanating from the flat sidewalls appears to range from $24^{\circ}-60^{\circ}$.

Less uncertainty appears in the measurements taken closer to the contoured walls and the corners, especially when disregarding the measurements made at the lowest Reynolds numbers. When the Kulites are closer to the contoured walls, the disturbance propagation speed approaches $67-76 \%$ of the freestream speed and the disturbance angle ranges from $30-44^{\circ}$ at the higher Reynolds numbers. When the Kulites are closer to the corners, the disturbance propagation speed approaches $62-71 \%$ of the freestream speed and the disturbance angle ranges from $26-35^{\circ}$ at the higher Reynolds numbers. These results are much more consistent than for the flat sidewalls, as the coherence between the Kulites in these measurements is almost twice as high as it is for the flat sidewalls.

Computations done by Duan and Choudhari ${ }^{31}$ showed that the inclination of the Mach waves in an axisymmetric Mach-6 tunnel is approximately $30^{\circ}$ and the convection velocity of the disturbances is approximately $66 \%$ of the freestream velocity. The experiments done by Kistler and Chen ${ }^{32}$ showed that the convection speed of similar disturbances on the sidewall in the former JPL 20-inch Supersonic Wind Tunnel (now at NASA Langley Research Center) approaches $60 \%$ of the freestream velocity and remains relatively constant between Mach 3 and Mach 5. Reference 32 also shows that the convection speed for the eddies in the turbulent wall boundary layer should level off near $60 \%$ of the freestream velocity above Mach 3 . Laufer showed that a measurement of the convection speed of the disturbances in the same tunnel with two hot wires produced a convection speed of approximately $64 \%$ of the freestream velocity and a disturbance with Mach angle of approximately $26.7^{\circ}$ at Mach $5 .{ }^{27,28}$ Measurements by Raman ${ }^{33}$ show that the speed of the turbulent structures in the boundary layer of a Mach-7.4 flat plate are between 60 and $70 \%$ of the freestream 
velocity. These previous experimental and computational results provide a general range of speeds and angles in which the disturbances in the nozzle-wall boundary layer are expected to propagate. In comparison to the current data, these values are close to the lower range of values derived for the 20-Inch Mach 6 Tunnel, which is promising. More work needs to be done to improve the current measurements.

\section{B. Heat Transfer Fluctuations}

Measurements with the ALTP gauge were made using only the small rake positioned at a streamwise station of $z=2.238 \mathrm{~m}$. The power spectra for the heat transfer fluctuations as measured by the ALTP gauge are given in Fig. 17. These spectra appear to collapse to a single line for frequencies greater than $2 \mathrm{kHz}$ when the fluctuations are expressed as a percentage of the mean measurement for all but the lowest Reynolds number tested. A small peak is present near $30 \mathrm{kHz}$ for the higher unit Reynolds numbers tested and near $40 \mathrm{kHz}$ for the lowest unit Reynolds number tested. This peak is not present in the power spectra for the measurements with other sensors, so its presence in the ALTP measurements is surprising. The ALTP probe is $7.94 \mathrm{~mm}$ in diameter, which is much larger than the other probes to accommodate the larger size of the sensor body. For comparison, the other probes range from being a wire sensor $5-\mu \mathrm{m}$ in diameter to a maximum of $6.35 \mathrm{~mm}$ in diameter for the PCB probe. Previous computational ${ }^{34}$ and experimental ${ }^{35}$ studies have shown that the geometry of pitot probes used can affect the measurement of freestream disturbances. It is possible that this peak is a result of an unsteady bow shock ahead of the larger probe body.

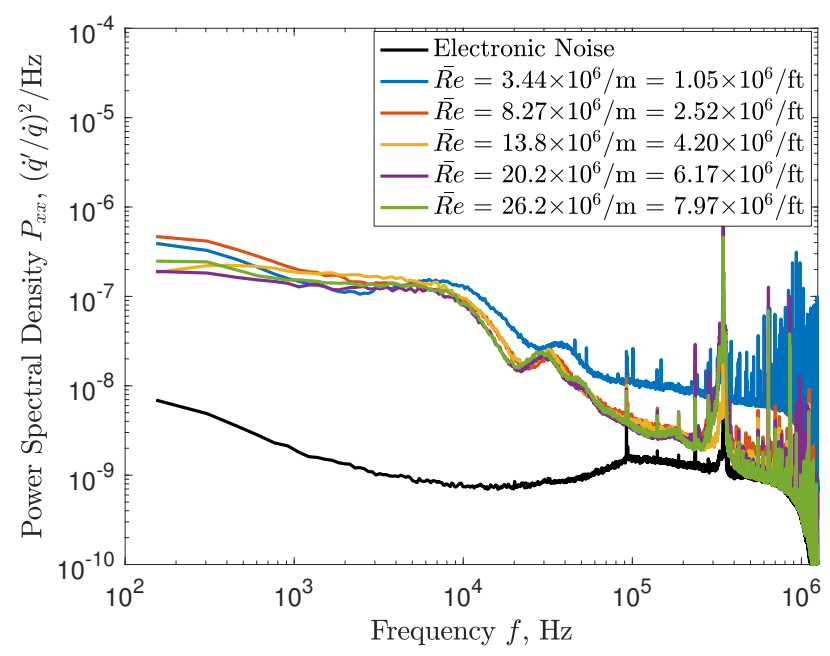

Figure 17: Power spectral density of freestream heat transfer fluctuations: $z=2.238 \mathrm{~m}, y=+9.53 \mathrm{~mm}$.

A large amount of high-frequency electronic noise is present in these measurements. Unlike the Kulite and PCB measurements, the ALTP measurements were only made with a single probe in the rake. Thus, the incoherent spectra could not be plotted here. A source of high-frequency electronic noise was identified as the servo motors for the model injection system. For these data, the servo motors for the yaw and pitch control were de-energized during data collection in order to eliminate that source, but some high-frequency electronic noise is still present. The source of this noise is as-yet unidentified, but is present in the other measurements.

The RMS fluctuations of the heat-transfer measurements is given in Fig. 18. These data are computed by integrating the power spectra in Fig. 17 from $100 \mathrm{~Hz}$ to $100 \mathrm{kHz}$ and then taking the square root. The RMS is fairly constant at 5-6\% of the stagnation point heat transfer for the range of Reynolds numbers. Some issues with the calibration of the ALTP gauges were noted in Ref. 20, so the measured heat flux at the stagnation point was compared to the Fay-Riddell equations for a hemisphere with the same radius as the ALTP probe. The Fay-Riddell equations for heat transfer at the laminar stagnation point were computed for a frozen boundary layer and a non-catalytic wall. ${ }^{36}$ These computed values differ from the measured heat transfer by up to 8 times, which could be due to a combination of inaccurate sensor calibration and the poor assumption of laminar flow on a hemisphere being comparable to that of a flat-faced probe. 


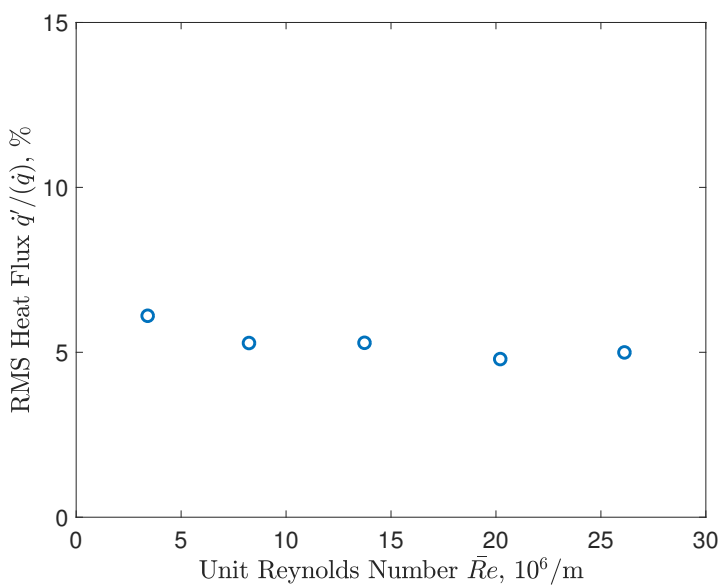

Figure 18: RMS amplitude of the freestream heat-transfer fluctuations up to $100 \mathrm{kHz}$.

\section{Mass-Flux Fluctuations}

The power spectra for the freestream mass-flux fluctuations as measured by the hot wires are given in Fig. 19. Two hot wires were mounted in the small rake and the rake was positioned at a streamwise station of $z=2.238 \mathrm{~m}$ with an orientation of $\phi=0^{\circ}$ and $\phi=90^{\circ}$. Again, the yaw and pitch servo motors for the model injection system were de-energized during the data acquisition period. Data were acquired with two calibrated wires simultaneously for multiple unit Reynolds numbers. The hot wires show some highfrequency noise as seen in the ALTP sensors as well as some noise from the electric heaters in the facility. Otherwise, the shape of the spectra show elevated broadband signal from $400 \mathrm{~Hz}$ to approximately $30 \mathrm{kHz}$, where much of the signal starts to roll off.

The RMS mass flux fluctuations were computed by integrating the spectra between $100 \mathrm{~Hz}$ and 100 $\mathrm{kHz}$ to compare data to Stainback and Kubendran's measurements. ${ }^{4}$ These data are displayed in Fig. 20. The present data show good agreement with the measurements made in Ref. 4. The normalized freestream mass-flux fluctuations appeared to be constant regardless of the stagnation pressure, except at the lowest Reynolds number. The present measurements show that the mass flux fluctuations vary from approximately $1.7 \%$ of the freestream to $2 \%$ of the freestream at unit Reynolds numbers greater than $8 \times 10^{6} / \mathrm{m}$. These values are slightly lower than the $2-3 \%$ fluctuations reported in Ref. 4 .

From the data shown in previous sections of this paper, it also appears that the freestream fluctuations at the lowest unit Reynolds numbers of the present measurements do not collapse with the other measurements. Thus, it is possible that the nozzle wall boundary layer is transitional at the unit Reynolds numbers below approximately $6 \times 10^{6} / \mathrm{m}$. This may help to explain why the freestream fluctuations are higher for the lower unit Reynolds numbers, as a transitional boundary layer can contain higher-amplitude disturbances than a fully-turbulent boundary layer.

For comparison to different types of anemometers, the data are compared to the results published by Chokani et al., who used a constant current anemometer (CCA) and a constant voltage anemometer (CVA) with tungsten wire probes. ${ }^{11}$ Chokani et al. results indicate that the freestream fluctuations of mass flux are somewhere between 0.62 and $1.01 \%$ for these two types of anemometers. These results were band-limited RMS fluctuations, so to compare the present measurements with the results of Chokani et al., the spectra of the present results were also integrated from $1-40 \mathrm{kHz}$, as in Ref. 11. The comparison of the present experiments to those of Ref. 11 are presented in Fig. 21.

As shown, the present measurements remain almost twice as large in amplitude as those presented by Chokani et al. This may be due to the differences between the calibration method used for the present measurements and the calibration used for the measurements in Ref. 11. The current measurements were acquired at a high overheat value such that the hot wire was primarily sensitive to mass flux. Chokani et al. used the relative sensitivity coefficients given by Comte-Bellot ${ }^{37}$ to determine the mass-flux and totaltemperature fluctuations for a range of overheat values. The tungsten-wire probes used by Chokani et al. could not be run at a high overheat due to the oxidation temperature of the tungsten. 


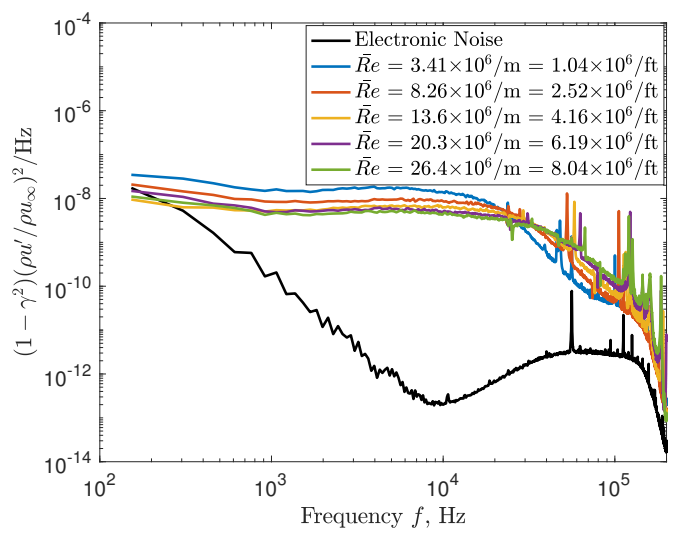

(a) $x=+9.53 \mathrm{~mm}$.

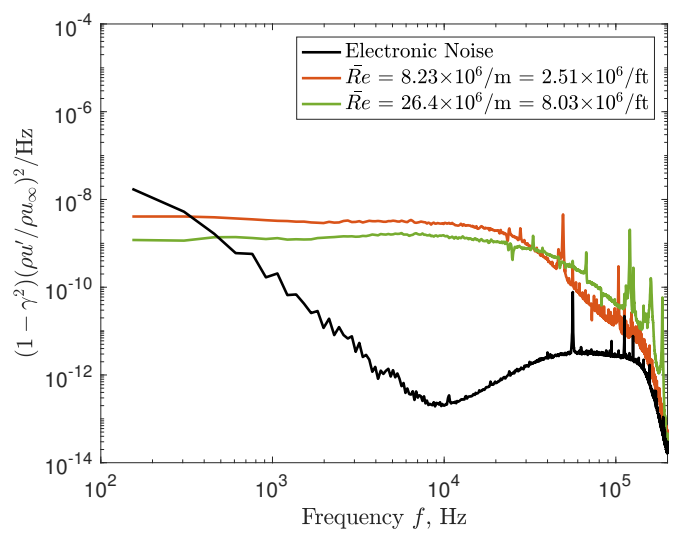

(c) $y=+9.53 \mathrm{~mm}$.

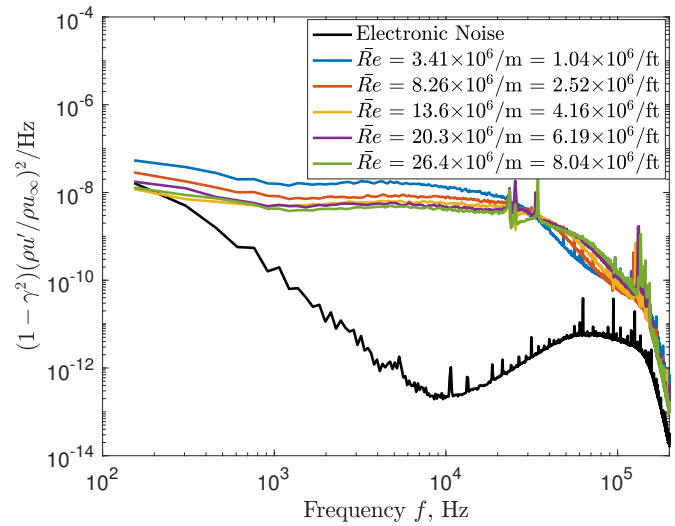

(b) $x=-9.53 \mathrm{~mm}$.

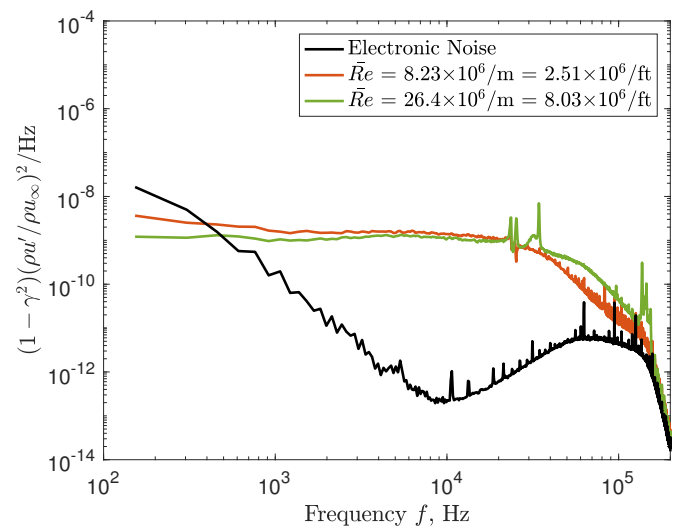

(d) $y=-9.53 \mathrm{~mm}$.

Figure 19: Power spectral density of freestream mass-flux fluctuations at $z=2.238 \mathrm{~m}$.

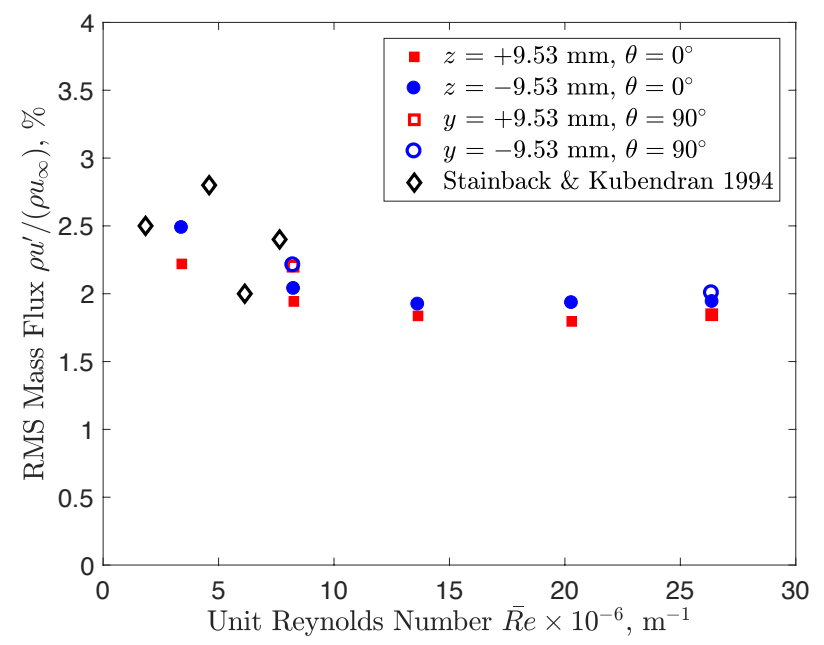

Figure 20: RMS fluctuations of mass flux measured with a CTA.

Using the methods described in Section III.C, an attempt was made to find the speed and the angle of disturbances propagating along the wall as measured by the hot wire. Unfortunately, the placement of the 


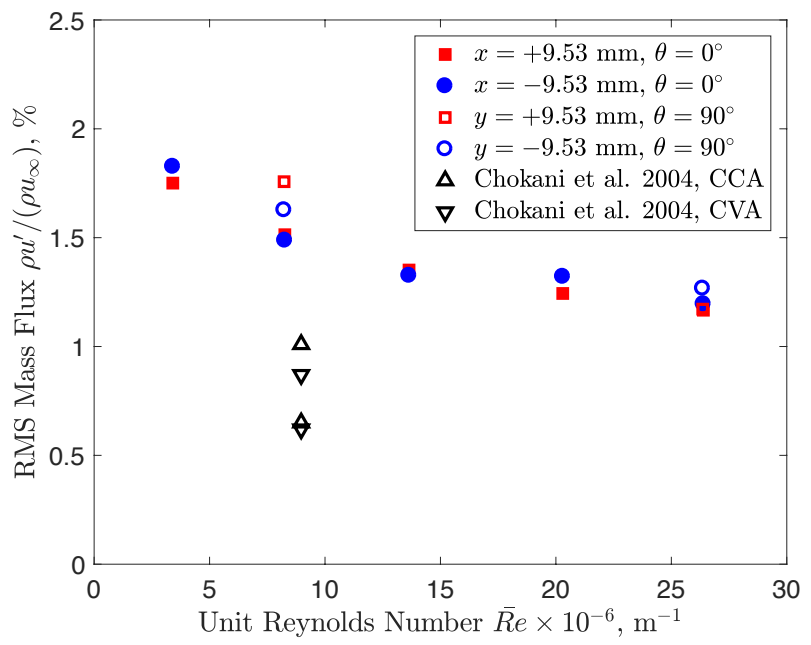

Figure 21: RMS fluctuations of mass flux measured with a CTA compared to measurements with a CCA and CVA.

hot wire probes at the centerline causes the wires to be equally susceptible to radiated noise from the walls that are parallel to the wires. The coherence for the wires at a variety of Reynolds numbers are provided in Fig. 22. In the same frequency band where the Kulite transducers showed some coherence, the hot wires also have a similarly low coherence of $\gamma^{2}<0.2$. Unlike the Kulite transducers, however, there does not appear to be a distinct peak in the coherence except for the highest Reynolds number case when the rake is oriented at $\phi=0^{\circ}$. At a unit Reynolds number of approximately $26 \times 10^{6} / \mathrm{m}$, the peak in the coherence is located at $2594 \mathrm{~Hz}$ in Fig. 22a. However, inspection of the angle of the cross-spectra between the two signals measured by the hot wires shows that there are no phase differences between the signals.

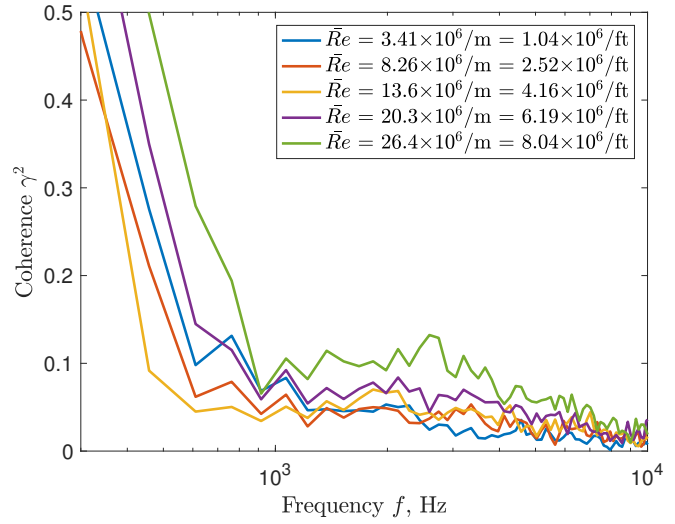

(a) $\phi=0^{\circ}$.

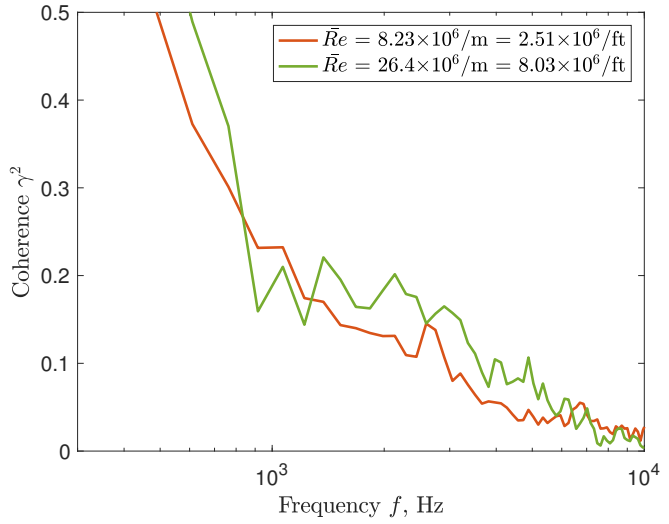

(b) $\phi=90^{\circ}$.

Figure 22: Mean-squared coherence for hot wire measurements at $z=2.238 \mathrm{~m}$.

\section{Focused Laser Differential Interferometry}

The spectra shown in Fig. 24 are of relative density fluctuations in the 20-Inch Mach 6 freestream for a sweep of unit Reynolds numbers tested and two flow-off conditions. The absolute sensitivity of this instrument to density fluctuations has not yet been determined, so again, these spectra are in arbitrary units. To obtain an absolute sensitivity, the instrument would have to be calibrated. The frequency response of this instrument is also unknown, but estimated as discussed in Section III B. The spectra shown in Fig. 24 have not been 


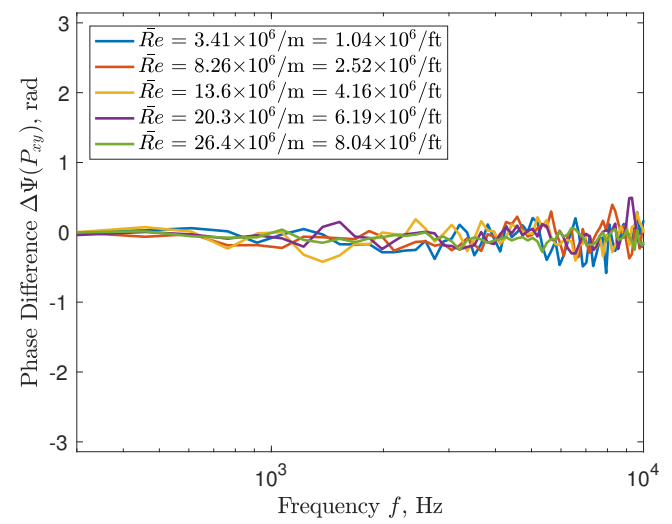

(a) $\phi=0^{\circ}$.

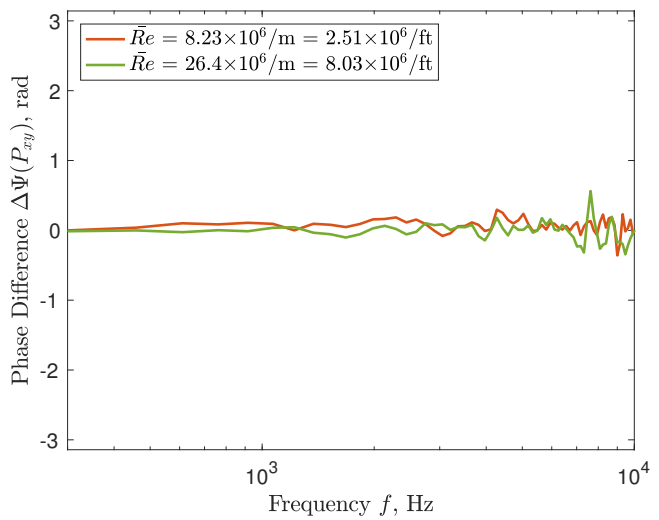

(b) $\phi=90^{\circ}$.

Figure 23: Mean-squared coherence for hot wire measurements at $z=2.238 \mathrm{~m}$.

normalized by the estimated instrument response functions.

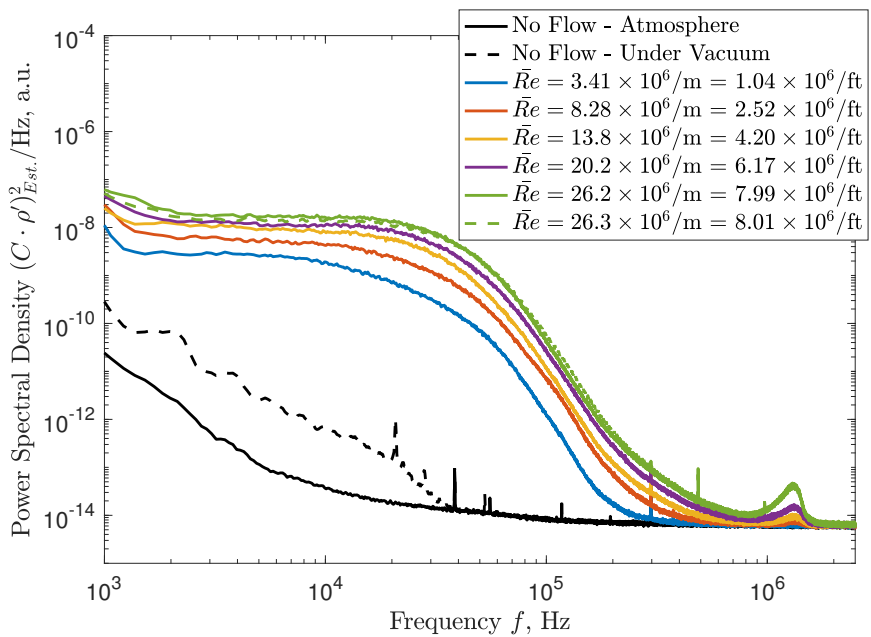

Figure 24: Power spectral density of measurements made with the FLDI for various Reynolds numbers.

The solid black curve in Fig. 24 shows the FLDI measurements with no flow at ambient conditions. The very-narrow spikes in the $20-\mathrm{kHz}$ to $1-\mathrm{MHz}$ region are from unidentified electronic noise. The dashed black curve in Fig. 24 shows the FLDI measurements with no flow while the tunnel is at vacuum. This curve shows that the instrument is sensitive to the fluctuations caused by slow leaks in the test box and thus may not show a true noise floor for the FLDI.

The main feature of the flow-on data in Fig. 24 is the flat, broadband nature of the freestream density fluctuations from 1-30 kHz, with a high-frequency roll-off that looks similar to the estimated roll-off calculated for the instrument. The solid and dashed green curves illustrate the repeatability of the combined instrument for two runs at the highest Reynolds number. This repeatability was consistent for the other Reynolds numbers as well.

A comparison of the power spectra of measured pressure fluctuations to the power spectra of measured density fluctuations is given in Fig. 25. Note that the quantities measured by the Kulite and PCB pressure transducers and the FLDI instrument are different: the probes measure fluctuations in pitot pressure while the FLDI measures fluctuations in density. The comparison at lowest unit Reynolds number tested is given in Fig. 25a and highest unit Reynolds number tested in Fig. 25b. In these figures, the power spectra of the Kulite and PCB measurements are truncated to the quoted bandwidths of each sensor. At the lowest 
Reynolds number, the slope and roll-off of the FLDI and Kulite spectra agree well for the bandwidth of $1 \mathrm{kHz}$ to $20 \mathrm{kHz}$. The power spectra of the PCB probe data in Fig. 25 appears to deviate from the FLDI measurement for both Reynolds numbers shown here. Since the frequency response of each measurement technique is unclear, it is difficult to state which method provides a more accurate representation of the flow. A major difference is that the FLDI is less sensitive to the electronic noise.

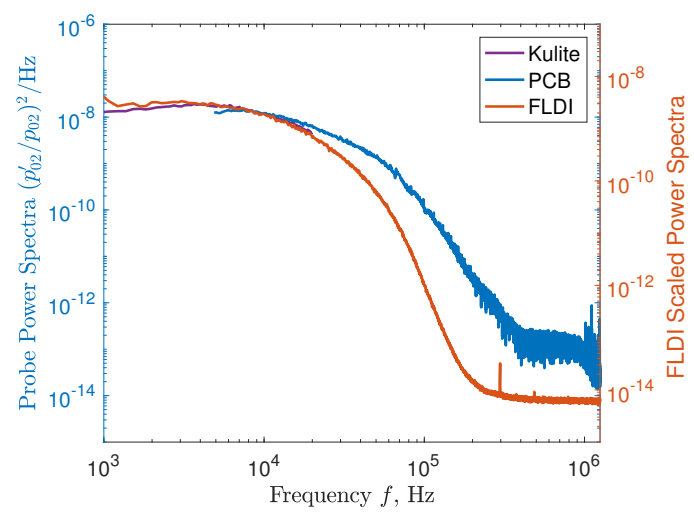

(a) $\overline{R e}=1.04 \times 10^{6} / \mathrm{ft}=3.41 \times 10^{6} / \mathrm{m}$.

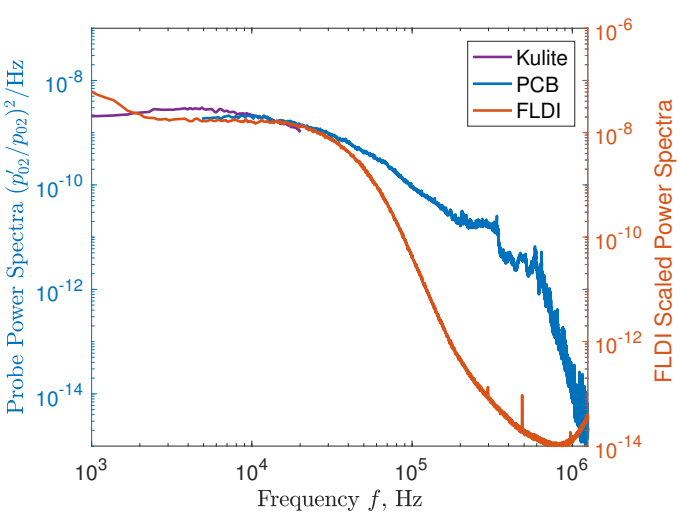

(b) $\overline{R e}=7.99 \times 10^{6} / \mathrm{ft}=26.3 \times 10^{6} / \mathrm{m}$.

Figure 25: Qualitative comparison of FLDI spectra and pressure spectra at two unit Reynolds numbers.

Similar effects are seen in the higher Reynolds number case (Fig. 25b). However, there are now some discrepancies between the Kulite and FLDI system at the lower frequencies as well. The FLDI measurements showed an increase in noise at frequencies below $1 \mathrm{kHz}$. Accelerometers were placed on the optical breadboard where the FLDI system was mounted, and no appreciable vibrations were measured up to $10 \mathrm{kHz}$ on the particular system. Thus, the increase in noise at frequencies below $1 \mathrm{kHz}$ may be due to the spacing of the two FLDI beams. A close spacing of the FLDI beams cannot measure disturbances with longer wavelengths, as these point measurements will not show a difference in phase. The FLDI also contains a peak at 1.3$1.4 \mathrm{MHz}$, which is not seen in the pressure measurements. The PCB data were only sampled at $2.5 \mathrm{MHz}$ and filtered at $1 \mathrm{MHz}$, so these peaks would not be evident in the spectra for the PCB measurements.

A comparison of the RMS fluctuations measured by the FLDI to the pressure fluctuations is given in Fig. 26. The RMS of the fluctuations measured by the FLDI were integrated from $1-100 \mathrm{kHz}$, and then linearly scaled by some factor of the unit Reynolds number to match the RMS pressure fluctuation measurement at the lowest Reynolds number tested. Thus, the RMS fluctuations of the FLDI measurements are presented in arbitrary units. Only the data from a single PCB probe at a single location is shown in this figure for clarity. These fluctuations appear to be similar to the measurements by the PCB probe. In comparing the spectra, the FLDI appeared to be less sensitive than the pressure sensors at higher frequencies, which may explain the slight discrepancy in measurements.

\section{Summary}

Measurements of the freestream pressure, heat-flux, and mass-flux fluctuations were made in the 20Inch Mach 6 Tunnel. These measurements help quantify the quality of the freestream disturbance levels, which are important to the understanding of transition on test articles. Knowledge of the spatial and spectral variation of these quantities can help users of the facility determine placement and sizing of their test articles. Measurements were made farther forward of the stations tested in previous tests, which can provide in-flow conditions for parties interested in modeling the facility and the facility's influence on test articles.

Over time, changes have been made to the facility injection system, windows, etc. A comparison of the present pressure measurements to past pressure measurements appears consistent, indicating that little change in the flow quality has occurred within the last 6 years. A comparison of the present mass-flux measurements to past mass-flux measurements also appears consistent to those made nearly 25 years ago. Mass-flux measurements were also able to be made at much higher Reynolds numbers than previously tested, so limited information about the spectral content and RMS at the highest range of Reynolds numbers are now 


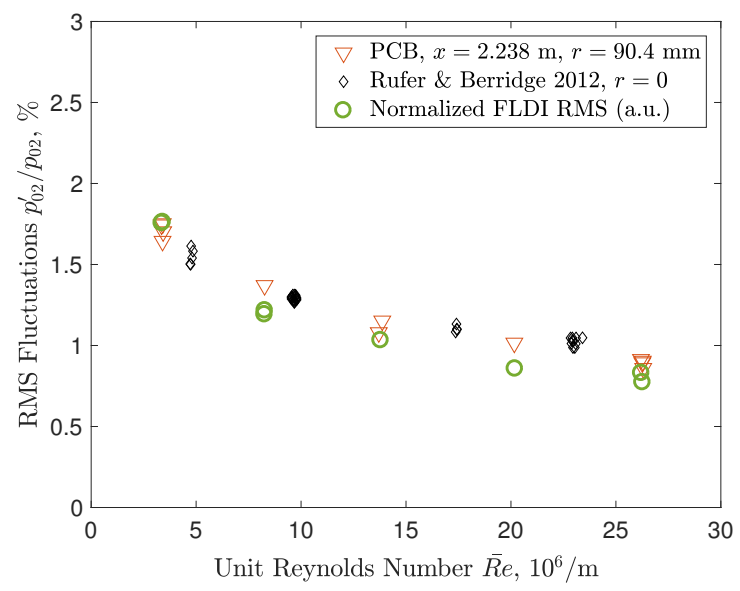

Figure 26: Qualitative comparison of FLDI RMS and RMS pressure fluctuations at a sweep of Reynolds numbers.

available. The fact that the facility changes over the years have not greatly affected the RMS fluctuations of pressure and mass-flux is encouraging.

The pressure and mass-flux measurements were also augmented by measurements of freestream fluctuations in heat transfer and density gradient. These were new measurement techniques that had not previously been utilized in freestream fluctuation characterization at NASA Langley. A limited sweep of Reynolds numbers at a single measurement station were made with an ALTP probe and again separately with the FLDI. The ALTP had a much larger probe body than the other probes used, and possible resonance effects due to this size were evident in the power spectra. The FLDI measurements were uncalibrated for this test, and could only provide relative measurements of the amplitude of the density fluctuations. However, the measurements show that this instrumentation has the potential to provide higher bandwidth measurements than some of the other techniques currently available while being less affected by electronic noise.

New information on the structure of disturbances emanating from the nozzle walls of this facility were also derived from the pressure measurements. A derivation of the disturbance angles shows that the waves propagate at an angle approximately $27-46^{\circ}$ and the speed of that disturbance is approximately $63-81 \%$ of the freestream speed. This is consistent with some computations of the disturbance angles seen in similar facilities. Future work will use probes placed closer to the wall and longer record lengths to attempt to increase the signal of the measurements made by the probes.

As changes to this facility occur, it is important to document if there are any changes to the fluctuation levels and frequency content of the freestream flow. Understanding the amplitude and content of the fluctuating quantities in the freestream can lead to a better understanding of their effects on data taken in ground test facilities. Facility users can also use these data to determine the best location for their models. Further applications of these measurements include the incorporation of this information into computational models of the facility as well. As the state-of-the-art methods for transition prediction and turbulence modeling improve, more information will be required to simulate the effects of the environment on test articles and real vehicles.

\section{Acknowledgements}

This experiment was made possible by the Hypersonics Technology Project as part of the Boundary Layer Transition working group under the Vehicle Technologies sub-project. The focused laser differential interferometry development and support for Steve Jones, who aided in the setup and design of this technique, was provided by the Transformational Tools and Technologies project. Support for this test was provided by facility technicians and engineers: Johnny Ellis, Grace Gleason, Kevin Hollingsworth, Sheila Wright, and Jonathan Crider. The rakes for this test were provided by Shann Rufer and Matthew Rhode and the probes were fabricated by Wayne Geouge and Mark Roth. Preparation of these probes and the instrumentation for this test occurred in the Probe Calibration Tunnel at NASA Langley Research Center with the aid of 
Rhonda Difulvio and Ricky Clark. Mark Wason calibrated the PCB probes in a small shock tube at Purdue University.

\section{References}

${ }^{1}$ Pate, S. R. and Schueler, C. J., "Radiated Aerodynamic Noise Effects on Boundary-Layer Transition in Supersonic and Hypersonic Wind Tunnels," AIAA Journal, Vol. 7, No. 3, Mar 1969, pp. 450-457.

${ }^{2}$ Stainback, P. C., "Hypersonic Boundary-Layer Transition in the Presence of Wind-Tunnel Noise," AIAA Journal, Vol. 9, No. 12, Dec 1971, pp. 2475-2476.

${ }^{3}$ Beckwith, I. E., T. R. Creel, J., Chen, F.-J., and Kendall, J. M., "Free-Stream Noise and Transition Measurements on a Cone in a Mach 3.5 Pilot Low-Disturbance Tunnel," Technical Paper NASA-TP-2180, NASA Langley Research Center, Hampton, VA 23681, September 1983.

${ }^{4}$ Stainback, P. C. and Kubendran, L. R., "The Measurement of Disturbance Levels in the Langley Research Center 20-Inch

Mach 6 Tunnel," Contractor Report NASA-CR-4571, NASA Langley Research Center, Hampton, VA 23681, March 1994.

${ }^{5}$ Schneider, S. P., "Effects of High-Speed Tunnel Noise on Laminar-Turbulent Transition," Journal of Spacecraft and Rockets, Vol. 38, No. 3, May-June 2001, pp. 323-333.

${ }^{6}$ Saric, W. S., Reed, H. L., and Kerschen, E. J., "Boundary-Layer Receptivity to Freestream Disturbances," Annual Review of Fluid Mechanics, Vol. 34, 2002, pp. 291-319.

${ }^{7}$ Schneider, S. P., "Development of Hypersonic Quiet Tunnels," Journal of Spacecraft and Rockets, Vol. 45, No. 4, 2008, pp. $641-664$.

${ }^{8}$ Balakumar, P. and Chou, A., "Transition Prediction in Hypersonic Boundary Layers Using Receptivity and Freestream Spectra," AIAA Journal, Vol. 56, No. 1, January 2018.

${ }^{9}$ Marineau, E. C., "Prediction Methodology for Second-Mode-Dominated Boundary-Layer Transition in Wind Tunnels," AIAA Journal, Vol. 55, No. 2, February 2017, pp. 484-499.

${ }^{10}$ Kegerise, M. A., Sheplak, M., and Spina, E. F., "Calibration of a Constant-Temperature Hot-Wire Anemometer in a Mach 6 Air Flow," Technical Report MAME-95-402, Syracuse University Center for Hypersonics, Department of Mechanical and Aerospace Engineering, Syracuse University, Syracuse, New York, 1995.

${ }^{11}$ Chokani, N., Shiplyuk, A. N., Sidorenko, A. A., and McGinley, C. B., "Comparison Between a Hybrid Constant-Current Anemometer and Constant-Voltage Anemometer in Hypersonic Flow," AIAA 2004-2248, June 2004.

${ }^{12}$ Rufer, S. J. and Berridge, D. C., "Pressure Fluctuation Measurements in the NASA Langley 20-Inch Mach 6 Wind Tunnel," AIAA Paper 2012-3262, June 2012.

${ }^{13}$ Berger, K., Rufer, S., Hollingsworth, K., and Wright, S., "NASA Langley Aerothermodynamics Laboratory: Hypersonic Testing Capabilities," AIAA Paper 2015-1337, January 2015.

${ }^{14}$ PCB Piezotronics, Inc., Model 132A31 Micro ICP Pressure Sensor, $140 \mathrm{mV} / \mathrm{psi}$, pigtail conn. (for high frequency): Installation and Operating Manual.

${ }^{15}$ Berridge, D. C., Generating low-pressure shock waves for calibrating high-frequency pressure sensors, Ph.D. thesis, Purdue University, West Lafayette, Indiana, 2015.

${ }^{16}$ Gray, K. A., Chynoweth, B. C., Edelman, J. B., McKiernan, G. R., Wason, M. P., and Schneider, S. P., "Boundary-Layer Transition Measurements in the Boeing/AFOSR Mach-6 Quiet Tunnel," AIAA Paper 2017-0068, January 2017.

${ }^{17}$ Hurst, A. M., Olsen, T. R., Goodman, S., VanDeWeert, J., and Shang, T., "An Experimental Frequency Response Characterization of MEMS Piezoresistive Pressure Transducers," Proceedings of ASME Turbo Expo 2014: Turbine Technical Conference and Exposition, June 2014, GT2014-27159.

${ }^{18}$ Roediger, T., The Atomic Layer Thermopile - A New Heat Transfer Measurement Technique in Fluid Mechanics and Thermodynamics, Ph.D. thesis, University of Stuttgart, Stuttgart, Germany, 2010.

${ }^{19}$ Kegerise, M. A. and Rufer, S. J., "Unsteady Heat-Flux Measurements of Second-Mode Instability Waves in a Hypersonic Flat-Plate Boundary," Experiments in Fluids, Vol. 57, No. 130, August 2016, pp. 1-15.

${ }^{20}$ Marineau, E. C., Lewis, D. R., Smith, M. S., Lafferty, J. F., White, M. E., and Amar, A. J., "Investigation of Hypersonic Laminar Heating Augmentation in the Stagnation Region," AIAA Paper 2013-0308, January 2013.

${ }^{21}$ Parziale, N. J., Shepherd, J. E., and Hornung, H. G., "Differential Interferometric Measurement of Instability in a Hypervelocity Boundary Layer," AIAA Journal, Vol. 51, No. 3, March 2013, pp. 750-753.

${ }^{22}$ Parziale, N. J., Shepherd, J. E., and Hornung, H. G., "Free-stream density perturbations in a reflected-shock tunnel," Experiments in Fluids, Vol. 55, No. 2, January 2014, pp. 1665.

${ }^{23}$ Schmidt, B. E. and Shepherd, J. E., "Analysis of focused laser differential interferometry," Applied Optics, Vol. 54, No. 28, 2015, pp. 8459-8472.

${ }^{24}$ Fulghum, M. W., Turbulence Measurements in High-Speed Wind Tunnels Using Focusing Laser Differential Interferometry, Ph.D. thesis, The Pennsylvania State University, 2014.

${ }^{25}$ Bendat, J. S. and Piersol, A. G., Random Data: Analysis and Measurement Procedures, John Wiley \& Sons, Inc., 4th ed., 2010 .

${ }^{26}$ Settles, G. S. and Fulghum, M. R., "The Focusing Laser Differential Interferometer, an Instrument for Localized Turbulence Measurements in Refractive Flows," Journal of Fluids Engineering, Vol. 138, October 2016.

${ }^{27}$ Laufer, J., "Sound Radiation from a Turbulent Boundary Layer," International Symposium of the National Scientific Research Center: The Mechanics of Turbulence, Marseille, France, August-September 1961, pp. 381-393.

${ }^{28}$ Laufer, J., "Some Statistical Properties of the Pressure Field Radiated by a Turbulent Boundary Layer," Physics of Fluids, Vol. 7, No. 8, August 1964, pp. 1191-1197.

${ }^{29}$ Rhode, M. N. and DeLoach, R., "Hypersonic Wind Tunnel Calibration Using the Modern Design of Experiments," AIAA Paper 2005-4274, July 2005. 
${ }^{30}$ Bounitch, A., Lewis, D., and Lafferty, J., "Improved Measurements of "Tunnel Noise" Pressure Fluctuations in the AEDC Hypervelocity Wind Tunnel No. 9," AIAA Paper 2011-1200, Jan 2011.

${ }^{31}$ Duan, L. and Choudhari, M. M., "Numerical Study of Pressure Fluctuations due to a Mach 6 Turbulent Boundary Layer," AIAA 2013-0532, January 2013.

${ }^{32}$ Kistler, A. L. and Chen, W. S., "The fluctuating pressure field in a supersonic turbulent boundary layer," Journal of Fluid Mechanics, Vol. 16, No. 1, May 1963, pp. 41-64.

${ }^{33}$ Raman, K. R., "A Study of Surface Pressure Fluctuations in Hypersonic Turbulent Boundary Layers," Contractor Report NASA CR-2386, Nielsen Engineering \& Research, Inc. for NASA Ames Research Center, Mountain View, CA, February 1974.

${ }^{34}$ Chaudhry, R. S. and Candler, G. V., "Computing Measured Spectra from Hypersonic Pitot Probes with Flow-Parallel Freestream Disturbances," AIAA Journal, Vol. 55, December 2017, pp. 4155-4166.

${ }^{35}$ Chynoweth, B. C., Edelman, J. B., Gray, K. A., McKiernan, G. R., and Schneider, S. P., "Measurements in the Boeing/AFOSR Mach-6 Quiet Tunnel on Hypersonic Boundary-Layer Transition," AIAA 2017-3632, June 2017.

${ }^{36}$ Fay, J. A. and Riddell, F. R., "Theory of Stagnation Point Heat Transfer in Dissociated Air," Journal of the Aeronautic Sciences, Vol. 25, No. 2, February 1958, pp. 73-85,121.

${ }^{37}$ Comte-Bellot, G., "Hot-Wire Anemometry," Handbook of Fluid Dynamics, edited by R. W. Johnson, chap. 34, CRC Press, Boca Raton, FL, 1998, pp. 34-1-34-29. 